\title{
Inbreeding and inbreeding depression of early life traits in a cooperative mammal
}

\author{
JOHANNA F. NIELSEN, ${ }^{* \dagger}$ SINEAD ENGLISH,${ }^{\ddagger}$ WILL P. GOODALL-COPESTAKE, ${ }^{\star \S}$ \\ JINLIANG WANG, ${ }^{\dagger}$ CRAIG A. WALLING, ${ }^{*}$ ANDREW W. BATEMAN, ${ }^{\ddagger}$ LOESKE E. B. \\ KRUUK, ${ }^{\star}$ TIM H. CLUTTON-BROCK, ${ }^{\ddagger}$ JOSEPHINE M. PEMBERTON ${ }^{*}$ \\ ${ }^{*}$ Institute of Evolutionary Biology, School of Biological Sciences, University of Edinburgh, \\ West Mains Road, Edinburgh, EH9 3JT, UK. \\ ${ }^{\dagger}$ Institute of Zoology, Zoological Society of London, Regent's Park, London, NW1 4RY, UK. \\ ${ }^{\ddagger}$ Department of Zoology, University of Cambridge, Cambridge, CB2 3EJ, UK. \\ ${ }^{\S}$ British Antarctic Survey, Natural Environment Research, Cambridge, CB3 OET, UK.
}

Author for correspondence:

Johanna Nielsen, Institute of Evolutionary Biology, School of Biological Sciences, University of Edinburgh, West Mains Road, Edinburgh, EH9 3JT, UK.

Tel: +44 131650 5440; fax: +44 131650 6564; e-mail: johanna.nielsen@ed.ac.uk

Tables: 5

Figures: 5

Word count:

Running title: Inbreeding depression in meerkats

Keywords: Suricata suricatta; inbreeding; inbreeding depression; emergence mass; growth rate; juvenile survival 


\section{Abstract}

Mating between relatives often results in negative fitness consequences or inbreeding depression. However, the expression of inbreeding in populations of wild cooperative mammals and the effects of environmental, maternal and social factors on inbreeding depression in these systems are currently not well understood. This study uses pedigree-based inbreeding coefficients from a long-term study of meerkats (Suricata suricatta) in South Africa to reveal that $44 \%$ of the population have detectably non-zero $(F>0)$ inbreeding coefficients. $15 \%$ of these inbred individuals were the result of moderate inbreeding $(F \geq 0.125)$, although such inbreeding events almost solely occurred when mating individuals had no prior experience of each other. Inbreeding depression was evident for a range of traits: pup mass at emergence from the natal burrow, hind-foot length, growth until independence and juvenile survival. However, we found no evidence of significant inbreeding depression for skull and forearm length or for pup survival. This research provides a rare investigation into inbreeding in a cooperative mammal, revealing high levels of inbreeding, considerable negative consequences and complex interactions with the social environment.

\section{Introduction}

Inbreeding, or the mating of genetically related parents, typically causes a decline in offspring fitness, known as inbreeding depression (Lynch \& Walsh 1998). Extensive research on captive and laboratory populations has highlighted the importance of inbreeding depression for many aspects of our understanding of ecology, conservation and evolution. For example, the negative fitness consequences of inbreeding depression can place vulnerable populations at risk of extinction and ultimately act as selective evolutionary pressures on organisms' behaviours and life strategies (Keller \& Waller 2002). Despite an accumulated knowledge of 
inbreeding depression effects on captive and laboratory populations, we know much less about the occurrence and effects of inbreeding in wild populations (Crnokrak \& Roff 1999; Keller \& Waller 2002). Studying inbreeding in wild populations that experience different environmental conditions is important as the effects of inbreeding in wild populations may not be accurately represented in stable laboratory or captive settings (Keller \& Waller 2002; Pemberton 2008).

Although a growing body of work is now revealing inbreeding and inbreeding depression in wild animal systems (Keller \& Waller 2002), comparatively few studies have focused on cooperative species (but see Brown \& Brown 1998; Daniels \& Walters 2000; Hoogland 1992; Keane et al. 1996; McRae 1996; Richardson et al. 2004; Spiering et al. 2011). As cooperative species tend to live in family groups with close relatives of the opposite sex in near proximity the potential for inbreeding is high (Koenig \& Haydock 2004). Furthermore, there are unusually strong selection pressures favouring philopatry in cooperative species (Kokko \& Ekman 2002; Komdeur 1992; Solomon 2003), which raises the questions of whether individuals remain and breed in their natal group and whether regular inbreeding has purged the population of deleterious recessive alleles. Alternatively, individuals may increase their fitness by dispersing to avoid inbreeding and its negative fitness consequences. The well-documented negative effects of inbreeding may act as strong selective pressures against consanguineous matings and, consequently, cooperative species may have evolved particularly strong incest avoidance mechanisms (Koenig \& Haydock 2004; Pusey \& Wolf 1996). Although there is evidence to suggest that the further individuals move, the less likely they are to breed with close relatives (Schiegg et al. 2006; Szulkin \& Sheldon 2008) and evidence for kin recognition has been found in some species (Pusey \& Wolf 1996), little 
inbreeding research has focused specifically on cooperative mammals where social living may in fact generate the greatest opportunities for inbreeding to occur.

Inbreeding may have negative fitness consequences, but it may also be tolerated in certain circumstances where the costs of avoiding mating with kin are greater than the benefits gained by avoidance (Kokko \& Ots 2006; Waser et al. 1986). For some individuals (e.g. subordinates) consanguineous matings may represent their only opportunity for reproduction and thus the costs of discriminating between mates based on the degree of relatedness between potential mates may not outweigh the benefits of reproducing. Inbreeding may also be tolerated when the costs of incestuous matings for offspring viability are small relative to the inclusive fitness benefits of the increased representation of copies of an individual's genes in subsequent generations (Kokko \& Ots 2006; Waser et al. 1986). There is also a suggestion that the increased kinship within social groups that results from inbreeding may in fact promote or maintain cooperative behaviours in line with kin selection theory (Griffin \& West 2003; Hamilton 1963; Rossiter et al. 2005; West et al. 2002). Determining accurate levels of inbreeding and inbreeding depression in cooperative species will serve as a first step towards testing these ideas.

Several studies have demonstrated how the effects of inbreeding depression vary with environmental heterogeneity. More specifically, the magnitude of inbreeding depression has been shown to increase under more severe environmental conditions in both experimental systems (summarised in Fox \& Reed 2011) and wild populations (Keller et al. 1994; Keller et al. 2002; Marr et al. 2006). These findings suggest an interesting line of research into the social environments of cooperative mammals where (subordinate) members of a social group 
contribute to the post-natal rearing of offspring other than their own, often more so than the (dominant) parents themselves (Clutton-Brock 2002; Clutton-Brock et al. 2004). Subordinate helpers can have important long-term fitness effects on the offspring they help to raise and, to some extent, replace the maternal effects that are commonly found to govern the fitness of non-cooperative vertebrates (Jennions \& Macdonald 1994; Russell et al. 2002). Helpers have even been shown to compensate for reductions in maternal investment, in turn influencing the decisions mothers make, conditional on helper availability (Clutton-Brock et al. 2001; Russell et al. 2007a). Consequently, in cooperative systems, helpers may modify the social environment experienced by an inbred animal to such an extent that they alleviate the effects of inbreeding depression, in a similar way that environmental heterogenetiy has been shown to mediate inbreeding depression in other systems (see above).

To date the most precise and reliable estimates of individual inbreeding coefficients $(F)$ appear to be those derived from accurate genetically-validated multigenerational pedigrees (Pemberton 2008; Taylor et al. 2010). However, reconstructing pedigrees for wild populations can be difficult (Pemberton 2008). Genetic parentage assignment can be particularly problematic in cooperative species as individuals usually live in groups of close relatives who share alleles and consequently the power of parentage analysis can suffer from low allelic diversity (McRae \& Amos 1999; Nichols et al. 2010; Richardson et al. 2004). Thus, although several studies have reported the occurrence of inbreeding (Keane et al. 1996) and inbreeding depression (Brown \& Brown 1998; McRae 1996) in populations of cooperatively breeding vertebrates, few have yet determined the overall frequency of inbreeding and the effects of inbreeding depression in wild mammalian populations using genetically-validated, pedigree-derived inbreeding coefficients. 
The long-term Kalahari Meerkat Project (Clutton-Brock et al. 1999a; Russell et al. 2002) provides a rare opportunity to investigate inbreeding and inbreeding depression in a cooperatively-breeding mammal. Meerkats (Suricata suricatta, Schreber 1776) are small, desert-adapted mongooses that live in groups of 2-50 (Doolan \& Macdonald 1999). These groups contain a dominant pair, which is responsible for $80-90 \%$ of the group's reproductive output (Griffin et al. 2003; Spong et al. 2008). The remainder of the group are male and female subordinates that assist in raising the dominants' pups by babysitting them at the natal burrow and by feeding and teaching them to forage once they emerge, at approximately three weeks of age (Clutton-Brock et al. 2001; Thornton \& McAuliffe 2006). Although subordinates of both sex are physiologically capable of breeding, they appear to avoid mating with (related) group members (Griffin et al. 2003). Furthermore, subordinate females are generally prevented from breeding by acts of aggression, eviction and/or infanticide from the dominant female (Clutton-Brock et al. 1998). Subordinate females can however spontaneously lactate to the dominant female's newborn pups - a behaviour termed allolactation (Scantlebury et al. 2002). Suckling seldom occurs outside the burrow and thus little is known about the extent and duration of allolactation in meerkats, however allolactating females can be clearly identified by enlarged nipples and surrounding flattened areas of fur that indicate suckling (Scantlebury et al. 2002). Meerkat pups generally reach nutritional independence at 90 days and start contributing significantly to cooperative behaviours within the group as sub-adults at 180 days (Clutton-Brock et al. 2001). Previous genetic analyses of breeding success in the same population concluded that the male-biased dispersal pattern of meerkats acts, in part, as an inbreeding avoidance mechanism (Griffin et al. 2003; Spong et al. 2008). At the time of this previous work, there were insufficient generations available to construct a pedigree for the study population, but in the years since, 
continued data collection has enabled a genetic pedigree to be constructed and hence a pedigree-based investigation of inbreeding to be undertaken.

Strictly speaking, 'inbreeding depression' refers to a loss of fitness, whereas in this paper we investigate inbreeding depression in a series of early life traits. Fitness describes the ability of organisms to both survive and reproduce but accurate long-term measures of fitness are often difficult to collect from wild populations. Although some studies have investigated the effects of inbreeding on fitness measures directly (e.g. Keller 1998; Kruuk et al. 2002; Szulkin \& Sheldon 2007), many have also investigated the effect of inbreeding on traits that are strongly associated with fitness, such as weight and morphological measures (e.g. Coltman et al. 1998; Coulson et al. 1998; Slate \& Pemberton 2002; Walling et al. 2011). In meerkats, offspring weight has positive consequences for both survival and acquiring dominance (Hodge et al. 2008; Russell et al. 2007b). Due to the large reproductive skew favouring dominants (Sharp \& Clutton-Brock 2010), total fitness is closely associated with dominance acquisition and thus offspring weight is likely to a trait that is strongly associated with fitness in meerkats. The extent to which offspring morphological traits and growth rates are associated with individual fitness in meerkats is less clear although studies in other species have found that both of these variables tend to be subject to strong directional selection due to the reproductive and survival advantages associated with large adult body size (Dmitriew 2011). Juvenile survival is an important fitness component in meerkats since survival of this stage is lower than at any other, yet meerkats rarely breed before they are one year old (Clutton-Brock et al. 1999b). Consequently, early-life meerkat weights, morphological measures, growth and survival are likely to be traits that are strongly associated with total 
fitness and thus appropriate measures in which to investigate the consequences of inbreeding on.

We present here tests for inbreeding depression in a range of early life traits in meerkats. Because these may be subject to maternal effects, and therefore dependent on the phenotype of the mother, we tested for associations between traits and the inbreeding coefficient of both the pup and the mother. The objectives of this research were three-fold: i) to document the extent and nature of inbreeding events in meerkats; ii) to quantify inbreeding depression in a range of early life morphometric and survival traits; and iii) to determine whether, and how, cooperative care affects the expression of inbreeding depression.

\section{Materials and Methods}

\section{Study population}

This study uses 16 years of data from the Kalahari Meerkat Project, which was established at

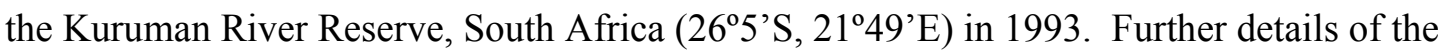
habitat and climate of the study system are provided elsewhere (Clutton-Brock et al. 1999a; Russell et al. 2002). All meerkats in the study population are individually recognisable and habituated to close observation $(<1 \mathrm{~m})$, and each group is visited up to two times a day. In addition to detailed behavioural observations for specific individuals, any changes in group composition and individual key life-history events are recorded, including the dates and details of births, deaths, dispersal, eviction, pregnancy, litter emergence and change of dominance events (Sharp \& Clutton-Brock 2010). Meerkats emerge from their natal burrow at approximately three weeks of age and are defined as 'pups' until they reach nutritional independence at approximately 90 days. Thereafter they are termed 'juvenile' (91-180 days); 
'sub-adult' (181-365 days) and 'adult' (>365 days) (Clutton-Brock et al. 1998; Doolan \& Macdonald 1999). The majority of meerkats in the study population are weighed upon emergence (emergence mass) from the natal burrow and up to three times daily thereafter, using a top-pan balance $( \pm 1 \mathrm{~g})$ (Clutton-Brock et al. 2003). Vernier callipers $( \pm 1 \mathrm{~mm})$ are used to measure skull length from the tip of the nose to the base of the skull, forearm length from the proximal end of the radius to the base of the carpals, and hind-foot length from the proximal end of the metatarsal to the distal end of the phalanges (excluding the claws). For DNA analysis 2-5 mm tissue sample from the tail tip of each pup is also taken at emergence (Spong et al. 2008). Tissue samples from recently habituated or immigrant adults were taken from anaesthetised or dead animals so that approximately $86 \%(n=1,563)$ of the total recorded population has now been sampled for tissue. Details of the DNA extraction and genotyping methods are provided in the Supporting Information.

\section{Pedigree and inbreeding coefficients}

The pedigree for the study population was reconstructed using a combination of microsatellite data, phenotypic descriptors and two parentage inference programs: COLONY2 (Wang 2004; Wang \& Santure 2009) and MASTERBAYES (Hadfield et al. 2006) (see Supporting Information for detailed pedigree construction methods). In brief, for COLONY2, all behavioural maternities of single litters were assumed correct and specified as such. For pups born to mixed maternity litters, candidate mothers were identified by consistent weight gain and visible abdominal distension over the 70-day gestation period followed by abrupt weight loss post-parturition (Clutton-Brock et al. 1999b). Candidate fathers included any known male alive in any group during a two week conception window (between 63 and 77 days prior to pup birth) (Clutton-Brock et al. 1999b). The probability of the true parents being in the 
candidate lists was set at 0.75 , both sexes were defined as polygamous and allele frequencies and genotyping error rates were provided (Supporting Table 2). Otherwise, default settings were used for all other program parameters. For MASTERBAYES, phenotypic descriptors including the sex, dominance status and the group of which an individual was a member of were provided for each month it was known to be alive. Additionally, monthly records of each female's gestational status (i.e. whether she was recorded as either being pregnant or had given birth) and whether a male was known to have roved were also provided as phenotypic descriptors. There is likely to be a relationship between these phenotypic descriptors and the pedigree structure and using them should increase the statistical power in parentage inference (Hadfield et al. 2006). Candidate mothers and fathers were restricted to individuals that were at least six months of age (to prevent sib paradox effects of true litter mates being misassigned parentage) (Thompson 1976; Thompson \& Meagher 1987). Candidate mothers were also restricted to members of the same natal group as the pup(s) in the three months leading up to (and including) a pup's birth. The Markov chain Monte Carlo (MCMC) estimation chain was run for 130,000 iterations, with a burn-in of 30,000 iterations and a thinning interval of 50 iterations. No further prior distributions were specified and default improper uniform priors were used (Hadfield et al. 2006). For both programs, only assignments with at least $80 \%$ individual confidence were considered in the final combination of program results, although the vast majority of these had individual confidence values above $95 \%$ (average = 97.57\%) and matched between the two programs (see Supporting Table 3). The pedigree was visualised and Wright's inbreeding coefficients $(F)$ for pups and mothers calculated using PEDIGREE VIEWER (http://www-personal.une.edu.au/ bbkinghor/pedigree.htm) (Kinghorn 1994). Pair-wise relatedness coefficients were obtained using the $\mathrm{R}$ software package PEDANTICS (http://wildevolution.biology.ed.ac.uk/awilson/pedantix.html) (Morrissey \& 
Wilson 2010). The resulting pedigree spans seven generations: between 1993 and early 2009 1,583 pups were born into the population and of these 1,539 and 1,277 have a resolved maternity and paternity, respectively. In the absence of parent-offspring matings, accurate Fvalues could only be determined for individuals with at least one grandparent assigned. Furthermore, the traits of interest and candidate parents were not available for the most recent pups. Consequently, we restricted our inbreeding depression analyses to only those pups born between 2000 and 2007 that had known $F$-values ( $n=963)$, although all pedigree information back to 1993 was used for the estimation of inbreeding coefficients. We follow Marshall et al. (2002)'s terminology of defining 'low' inbreeding as $F<0.125$, 'moderate' as $0.25>F \geq 0.125$ and 'high' as $F \geq 0.25$.

\section{Study traits}

\section{Response variables}

We examined the effect of mother's and pup's inbreeding coefficient on a number of early life traits including:

- Emergence mass (EM). To obtain a single estimate per individual, an average of all morning mass records obtained within seven days of the pup first being weighed upon emergence was calculated (mean number of mass records per pup $=3.120 \pm 1.570$ S.D.).

- Skeletal traits (skull (SL), forearm (FL) and hind-foot lengths (HL)). Skeletal traits were usually only measured once (upon emergence) and the earliest record was used if they were measured more than once. Records of the dates on which pups were recorded to have left their natal burrows with the group (at approximately four weeks of age) were used to restrict both the mass and skeletal records to only those that were 
obtained prior to a pup commencing foraging in order to avoid these measures being influenced by adult helper provisioning (Russell et al. 2002).

- Growth until independence (GI). Growth until independence (designated to occur at 90 days) was each individual's idealised growth rate at which it approaches a theoretical body mass. It was measured as the constant $(k)$ from a monomolecular curve (Gaillard et al. 1997) fitted for each individual through their mass records between age at emergence and 90 days (English et al. in press). The curve describes the relationship between mass and age $(t)$ as $M t=A^{*}\left(1-\mathrm{e}^{-k(t-t 0)}\right)$, with age-axis intercept $(t 0)$ and asymptotic mass $(A)$ fixed at approximate population mean levels $(t O=0$ and $A=730)$ (English et al. in press). The growth until independence parameter $(k)$ was scaled by a factor of 100 in the results table for ease of interpretation.

- Pup (PS) and juvenile (JS) survival. Pup survival was the period of time from emergence (at approximately three weeks) to independence (designated to occur at 90 days), and juvenile survival was from independence to sub-adult age (designated to occur at 180 days) (Table 1). For both survival periods the terminal event was pup death. Individuals that remained alive after each survival period were included as censored data points whereas individuals known or assumed with high confidence to have died during the specific survival period remained uncensored (Table 1).

Individuals that had emigrated out of the study population, were euthanized or were killed in road accidents were excluded in order to avoid upwardly biasing our results.

\section{Explanatory variables}

We tested for inbreeding depression in both offspring performance and maternal effects by inclusion of pup and the mother inbreeding coefficients $(F)$ respectively as explanatory 
Table 1 Summary statistics for traits: emergence mass (EM); skull (SL), forearm (FL) and hind-foot (HL) lengths; growth until independence (GI); pup survival (PS) and juvenile survival (JS). Sample sizes vary due to missing data for some variables. The growth until independence parameter $(k)$ has been scaled by a factor of 100 .

\begin{tabular}{lllll}
\hline & $n$ & Mean \pm S.D & Min. & Max. \\
\hline EM (g) & 422 & $113.229 \pm 26.258$ & 47 & 182.8 \\
SL $(\mathrm{mm})$ & 219 & $47.543 \pm 2.345$ & 36.9 & 52.4 \\
FL $(\mathrm{mm})$ & 171 & $30.549 \pm 2.247$ & 23.4 & 39.2 \\
HL $(\mathrm{mm})$ & 219 & $37.619 \pm 3.124$ & 28.5 & 49.5 \\
GI $(k)^{*}$ & 523 & $0.650 \pm 0.124$ & 0.2 & 1.2 \\
PS & 561 & ${ }^{\dagger} 0=501,1=60^{\ddagger}$ & - & - \\
JS & 497 & ${ }^{\dagger} 0=465,1=32^{\ddagger}$ & - & - \\
\hline
\end{tabular}

*There are fewer records for emergence mass and the skeletal measures as only records obtained prior to a pup foraging were used whereas all mass records were used to calculate growth until independence.

${ }^{\dagger}$ Mean, minimum and maximum values are not available for proportional hazards models. ${ }_{0}=$ individual was censored (i.e. survived or was removed from the population), $1=$ died during the specified time window. 
variables in the models. We also included a number of other pup-level fixed effects in our initial full models: pup age and pup age ${ }^{2}$ at measurement (relevant for emergence mass and skeletal traits: mean $=26$, range $=13-39.5$ days $(\mathrm{EM}) ;$ mean $=23$, range $=15-31$ days (skeletal traits)) were included to control for variation in the age at which pups were measured, as well as pup sex and litter size (mean=3.5, range $=1-7)$. Previous research on the population has found that non-pregnant dominant females are generally heavier than subordinates (Hodge et al. 2008), that there is reproductive senescence in females (Sharp \& Clutton-Brock 2010) and that mother's mass at conception is an important determinant of pup mass at weaning (Russell et al. 2003). Accordingly we also included mother's status (dominant/subordinate), mother's age and mother's age ${ }^{2}$ at pup birth, and mother's conception mass as fixed effects in our initial full models. As typical meerkat gestation is approximately 70 days (Clutton-Brock et al. 1998), the conception mass of mothers was taken as the average of all morning mass records 60-80 days prior to pup birth (mean number of mass records per mother $=8$ ). As a social, cooperatively breeding mammal, several traits have also been shown to be highly influenced by group-level factors (Clutton-Brock et al. 1999a; Clutton-Brock et al. 2001; Russell et al. 2003; Russell et al. 2002; Scantlebury et al. 2002) and consequently we included group size (total number of helpers aged $\geq 6$ months in the group at the time of pup birth, range $=1-36$ ) and lactator number (total number of lactators in the group including the mother, range $=1-8$ ) as fixed effects in our initial full models. Lactator number was calculated as the total number of females (including the mother) in the group that showed evidence of suckling at any point in the 26 days (average age at emergence mass weighing) after pup birth. Pup year of birth (range=2000-2007) was also fitted as a fixed effect factor in all models to control for environmental variation between years. Finally, as meerkats rarely breed in mid-winter but can breed throughout the year (Clutton-Brock et al. 1999b) and 
because both seasonality and rainfall influence growth in meerkats (English et al. in press; Russell et al. 2002), the season in which the pup was born (two-level factor of cold-dry: MaySeptember; hot-wet: October-April) and the total accumulated rainfall in the three months prior to pup birth were also included as fixed effects in our initial full models. Rainfall is thought to have a delayed positive effect on invertebrate abundance and thus rainfall in the months prior to pup birth may reflect the relative amount of food available to adult helpers at pup birth. Total accumulated rainfall in the three months prior to pup birth was extracted for the study site $\left(26^{\circ} 58^{\prime} \mathrm{S}, 21^{\circ} 49 \mathrm{E}\right)$ from the National Aeronautics and Space Administration online Rainfall Analysis Tool (http://disc2.nascom.nasa.gov/Giovanni/tovas/rain.GPCP.shtml) (Bateman et al. 2011). In order to account for repeated measures at various levels, mother ( $\max$ across traits=158), birth group ( $\max$ across traits $=32$ ) and litter ( $\max$ across traits=435) identifiers were included as random effects in the emergence weight, skeletal traits and growth models whereas only the litter identifier was included as a random effect in the survival models due to coxme package constraints. Litter was chosen as the random effect for this analysis as it is a unique identifier specific to each litter and contains information on both birth group and mother.

\section{Statistical analyses}

The emergence mass, skull, forearm and hind-foot lengths and growth until independence residuals were all normally distributed; these traits were therefore analysed using linear mixed models with normal errors in the lmer package in R (R Development Core Team 2009). The survival measures (PS and JS) were analysed in the R coxme model package, a Cox proportional hazards mixed effects model which is capable of handling a random and multiple fixed effects (R Development Core Team 2009). Initial full models contained all the 
explanatory variables above and were simplified using a stepwise approach in which the least significant terms (based on Wald statistics in lmer and comparison of AIC model value deviances in coxme) were removed incrementally until only significant $(p<0.05)$ terms remained or removal of a term decreased the model fit (Crawley 2007). In order to avoid comparing models with varying samples sizes (due to missing explanatory variables) models were compared using a subset of data which contained complete records for all explanatory variables and thus if non-significant terms were removed from the models, sample sizes generally increased. The robustness of the final models and the extent to which they were affected by multicollinearity was tested by removing any strongly correlated pair-wise variables (Supporting Table 4). As the coxme package reports the difference between the model in question $\left(\mathrm{AIC}_{\text {model }}\right)$ and the null model $\left(\mathrm{AIC}_{\mathrm{n}}\right)$, final minimal survival models were simplified where $-\left(\mathrm{AIC}_{\text {null }}-\mathrm{AIC}_{\text {model }}\right)$ was minimised.

In models where pup $F$ was significant, two-way interactions between pup $F$ and all other remaining fixed effects were tested. Pearson's correlations were estimated between all pairs of normally distributed response variables and sequential Bonferroni corrections on final minimum model $p$-values were also performed (Rice 1989). Sample sizes varied across the different response variables due to missing data and summary statistics for each trait are presented in table 1.

\section{Results}

\section{Occurrence of inbreeding}

A large proportion of the population was inbred to some extent. Of the 1,583 pups born into the population between 1993 and 2009, 474 of 1073 (44\%) of the individuals for whom 
inbreeding coefficients $(F)$ could be calculated had $F$ greater than zero (average $F=0.078$ ) (Fig. 1). The remaining population had $F=0(n=599)$ or $F=\mathrm{NA}(n=510)$. All inbred individuals had at least three known grandparents and 97\% had all four grandparents known ( $n=461)$ (Fig. 1). 91\% of known litters (average litter size=3.5) had the same parents and so identical $F$; in the remainder $(n=38)$, there was mixed paternity and $F$ varied between littermates.

Most cases of inbreeding were the result of fairly distant relatives mating. Although there were no instances of 'high' inbreeding at $F \geq 0.25$ (resulting from full sibling or parentoffspring matings) (Marshall et al. 2002), the distribution of non-zero inbreeding coefficients shows evidence of 'moderate' inbreeding at $0.25>F \geq 0.125$ ( 71 individuals in 28 litters). Moderately inbred pups resulted from either half-sibling $(n=13)$, grandparent-offspring ( $n=15)$ or full avuncular (aunt-nephew $(n=12)$ or uncle-niece $(n=31)$ matings) (Fig. 1). The distribution also reveals that 403 individuals ( $>85 \%$ of the inbred individuals) had 'low' inbreeding coefficients of $F<0.125$. For example, 127 individuals (in 42 litters) were inbred at $F=0.0625$ which resulted from first cousin, great grandparent-offspring or half avuncular matings (Fig. 1). Due to the depth of the pedigree and the inclusion of ancestral inbreeding events, many of the $F$ values in the population result from an accumulation of multiple inbreeding events in which distant relatives have mated across multiple generations (see example in Fig. 2).

$58.01 \%$ of all breeding pairs (including dominant pairs and other mated pairs) were related at $\mathrm{R}>0$. Inbred matings predominantly occurred between individuals who had no early-life exposure to each other: for all but eight pups (3 litters) with $F \geq 0.125$ the parents were either 


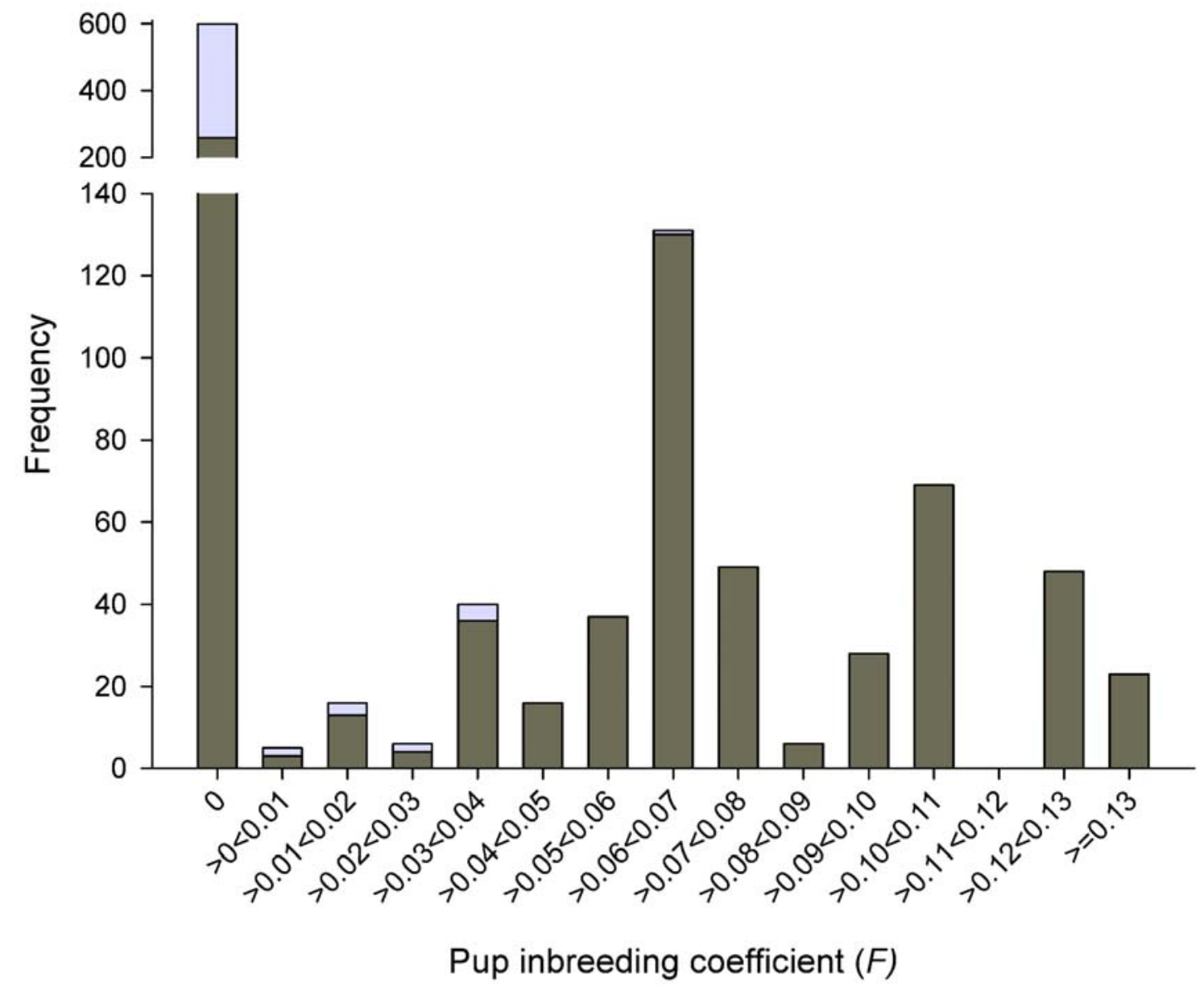

Fig. 1 The distribution of pup inbreeding coefficients $(F)(n=1,583 ; F=0=599 ; F>0=474)$. Dark and light grey shading indicates individuals that have all four $(n=719)$ or only three ( $n=354)$ known grandparents respectively. An additional 510 individuals had $F=\mathrm{NA}$. 


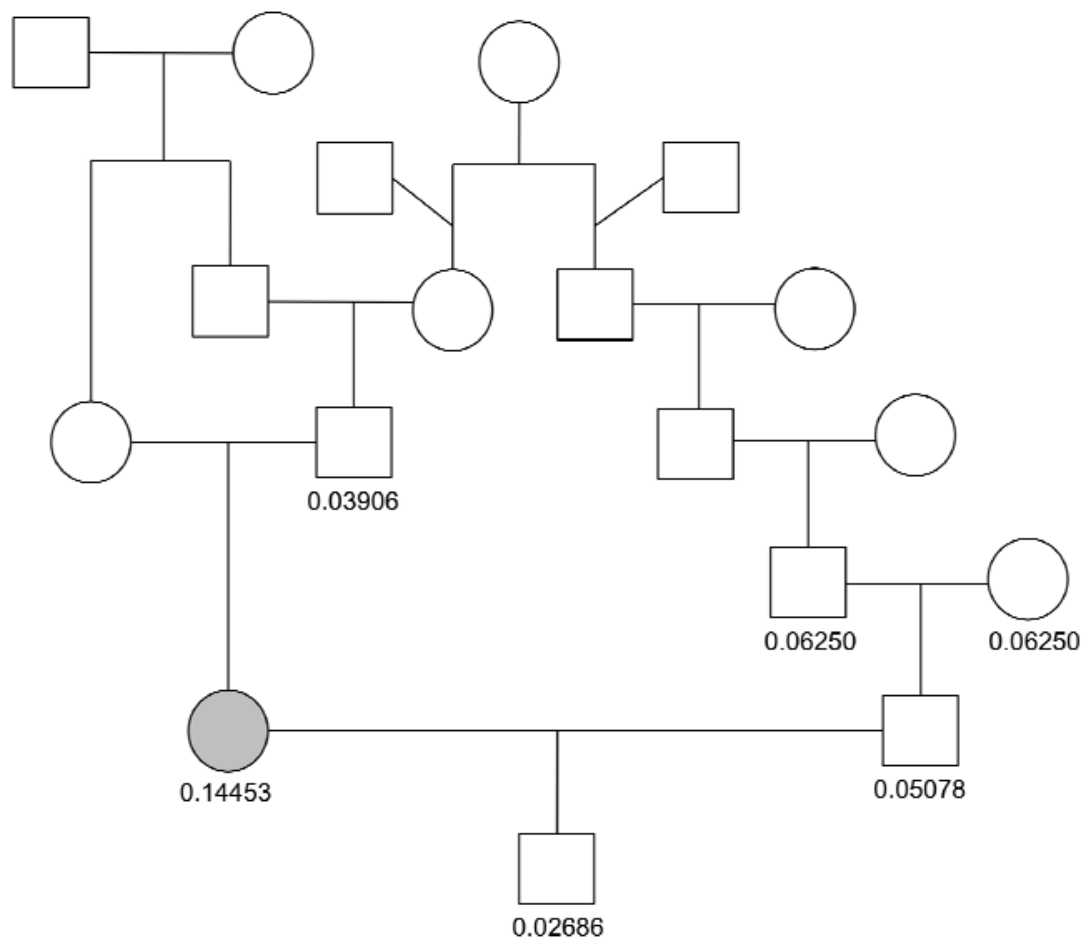

Fig. 2 Pedigree illustrating an example of an accumulation of multiple inbreeding events in which relatives mated across multiple generations. Circles and squares indicate females and males respectively. F-values are given below the shapes and are zero or unknown if absent. The individual at the base of the pedigree is inbred primarily via a half second cousin once removed mating loop, but its $F$-value is inflated by the fact that both its parents and three of its grandparents are also inbred. Similarly, the female in grey is the product of an avuncular mating, which would normally result in $F=0.125$ but is inflated here due to the fact her father is also inbred. 
born in different groups or one had left the same natal group prior to the other parent's birth. The three inbred litters produced by pairs that had spent time together in the same natal group resulted from a group split: a female became the dominant in a splinter group prior to two of her natal half brothers also immigrating into the group and mating with her.

Subordinate female and male breeders were more likely to produce inbred pups than dominants. $40 \%(349 / 867)$ of the pups born to dominant females had $F>0$ whereas $55 \%$ (86/156) of the pups born to subordinate females had $F>0$. Similar patterns were apparent for males: $33 \%(213 / 652)$ of the pups born to dominant males had $F>0$ whereas $56 \%(182 / 327)$ of the pups born to subordinate males had $F>0$. The z-ratios between these two independent proportions were both significant $(p<0.001)$ (Table 2).

\section{Analyses of traits}

Strong positive correlations were detected between all pairs of normally distributed traits (Table 3). We found no associations between mother's $F$ and offspring traits in any models, so we only present models testing for associations with pup's F. Any reported negative effects of pup $F$ remained after removal of either one of the strongly correlated variables.

\section{Emergence mass}

Emergence mass showed strong inbreeding depression, with inbred pups weighing less than those with $F=0$ (parameter estimate $=-156.30 \mathrm{~g} \pm 47.24$ S.E.; Table 4; Figs. $3 a \& 4 a$ ). For an individual with $F=0.078$ (the mean $F$ of the population) this parameter estimate translates into an approximately $10.9 \%$ reduction in emergence mass compared with individuals with $F=0$. The negative effect of $F$ remained when individuals with $F>0.13$ were removed (Fig. $3 a$ 
Table 2 Summary table of the inbreeding status of pups born to dominant and subordinate parents. Only pups with parents of known status and pups for whom $F$ could be calculated for were considered.

\begin{tabular}{lllll}
\hline & & Dominant & Subordinate & $p$ \\
\hline \multirow{2}{*}{ Female } & $F=0$ & $518(60 \%)$ & $70(45 \%)$ & 0.0005 \\
& $F>0$ & $349(40 \%)$ & $86(55 \%)$ & 0.0005 \\
Male & $F=0$ & $439(67 \%)$ & $145(44 \%)$ & $<0.0002$ \\
& $F>0$ & $213(33 \%)$ & $182(56 \%)$ & $<0.0002$ \\
\hline
\end{tabular}


Table 3 Pearson's correlations between normally distributed traits: EM, SL, FL, HL and GI. Numbers above the diagonal give the correlation value $(r)$ whereas numbers below give sample size $(n)$. Sample sizes vary due to missing data for some variables. All correlations are significant at $p<0.001$.

\begin{tabular}{|c|c|c|c|c|c|}
\hline & EM & SL & FL & HL & GI \\
\hline EM & - & 0.640 & 0.725 & 0.640 & 0.643 \\
\hline SL & 211 & - & 0.672 & 0.687 & 0.400 \\
\hline FL & 165 & 171 & - & 0.738 & 0.489 \\
\hline HL & 211 & 219 & 171 & - & 0.481 \\
\hline GI & 401 & 202 & 156 & 202 & - \\
\hline
\end{tabular}


a.)

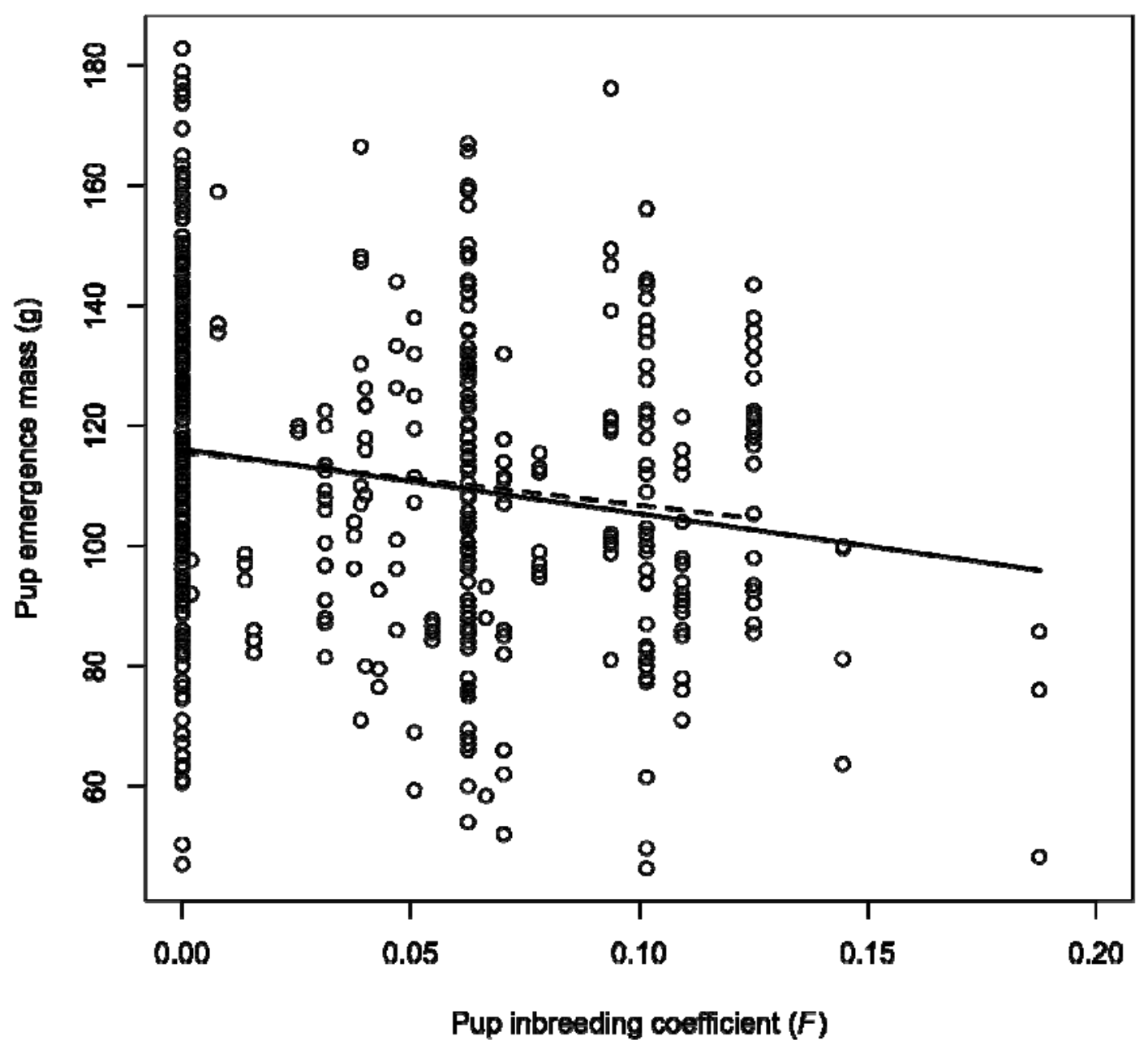


b.)

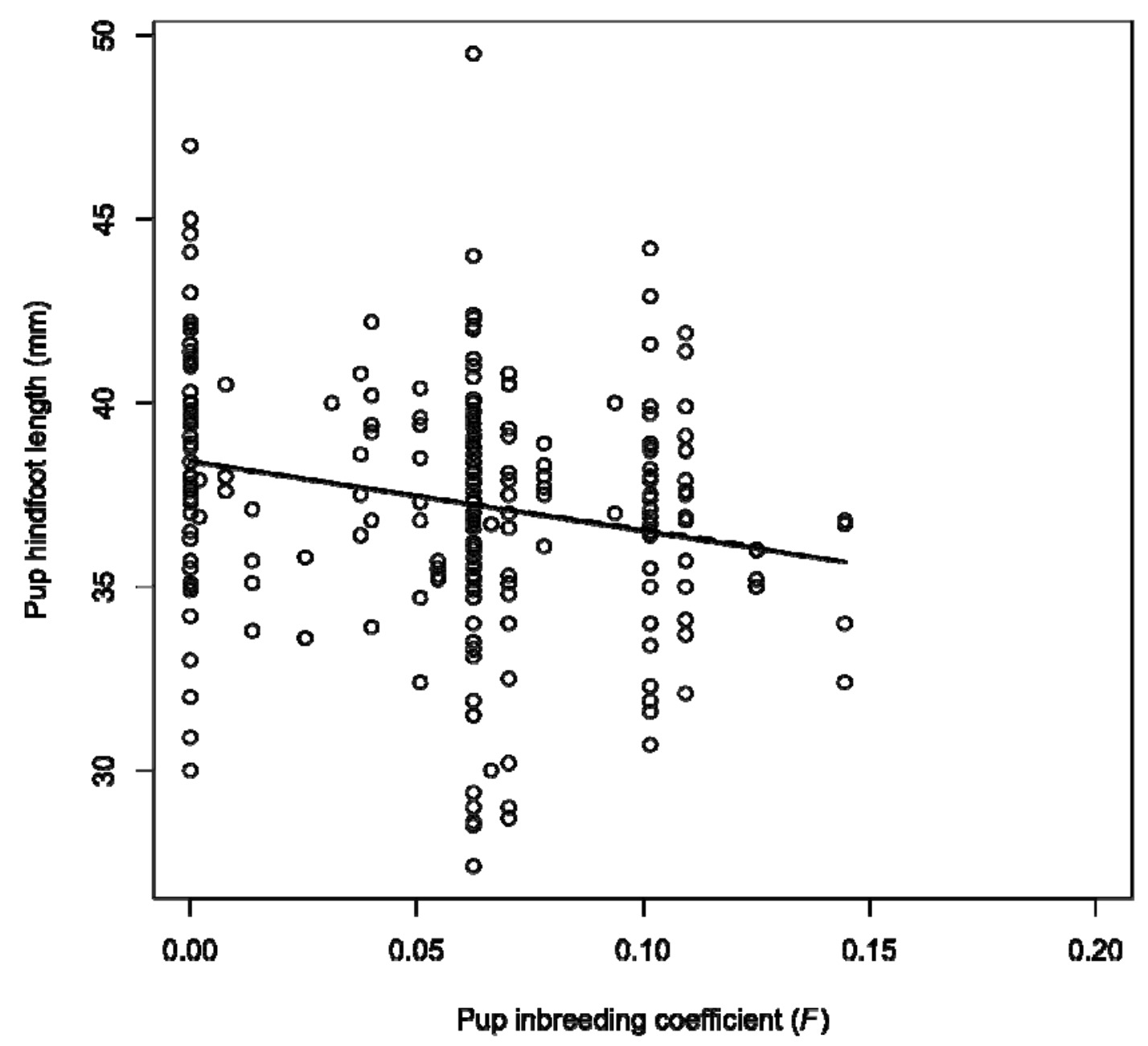


C.)

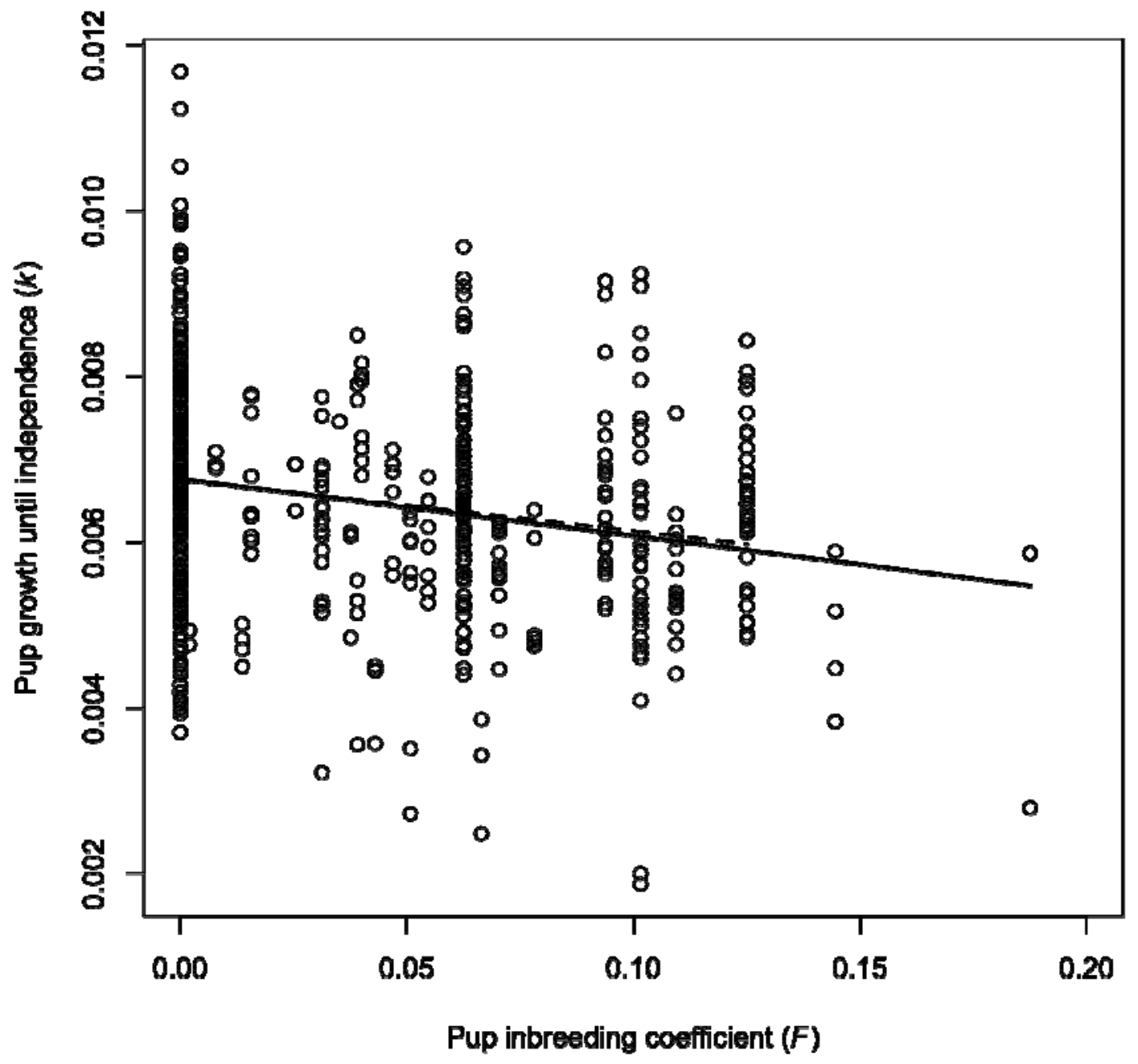

Fig. 3 The effect of pup inbreeding coefficient $(F)$ on $a$.) emergence mass $(\mathrm{g}), b$.) hind-foot length (mm), and c.) growth until independence $(k)$. Circles show individual pups and solid lines show effects predicted by the models. Dashed lines show that the negative trends remain even when $F>0.13$ values are excluded. 
dashed line). Lactator number had a significantly positive effect on pup emergence mass: inbred pups with three or more lactators emerged at equal or greater mass than $F=0$ pups suckled only by their mother (lactator number=1) (Fig. 4a). Additionally, there was a significant interaction between pup $F$ and lactator number (Table 4 ) in which emergence mass increased with increasing lactator number for both outbred and inbred pups with four or fewer lactators, but decreased for outbred pups born to groups with five or more lactators. This interaction remained even when moderately inbred $(F \geq 0.125)$ individuals were excluded from the model but disappeared when one exceptionally large subordinate breeding event (in which five subordinate females simultaneously gave birth to a total of 11 inbred pups in a group with eight lactators $(F$ range $=0.03906-0.10156))$ was removed. Removal of this breeding event also removed the main effect of pup $F$. There were also positive and negative effects of pup age and pup age ${ }^{2}$ on emergence weight respectively, and interactions between pup $F$ and pup age, pup $F$ and pup age ${ }^{2}$ (Table 4 ) such that the magnitude of the age effects on emergence weight were reduced for pups weighed at older ages.

\section{Skeletal traits (skull, forearm and hind-foot length)}

Hind-foot length showed some evidence of inbreeding depression whereas skull length and forearm length did not (hind-foot length parameter estimate $=-17.55 \mathrm{~mm} \pm 6.72$ S.E.) (Table 4 $\&$ Fig. $3 b$; see Supporting Information for skull and forearm length results). For an individual with $F=0.078$ this parameter estimate translates into an approximately $3.7 \%$ reduction in hind-foot length compared with individuals with $F=0$ and the negative effect of $F$ remained when individuals with $F>0.13$ were removed. (Fig. $3 b$ dashed line). There were no interactions between pup $F$ and any of the remaining variables in the final hind-foot length minimal model. 
Table 4 Summary of final minimal models of emergence mass, hind-foot length and growth until independence. Final minimal models were achieved by sequentially dropping the least significant terms based on Wald statistics until only significant $(p>0.05)$ terms remained. NS terms are not significant and therefore removed. Total deviance explained by all fixed effects $=3.067 \%$ (emergence mass), $4.291 \%$ (hind-foot length) and $1.195 \%$ (growth until independence). The percentage deviance of this that was attributable to $F$ is the change in deviance between the final minimal model and a model with $F$ removed, expressed as a proportion of the total deviance explained by all fixed effects in the final minimal model=8.1\% (emergence mass), $15.1 \%$ (hind-foot length) and $17.9 \%$ (growth until independence). The growth until independence parameter $(k)$ has been scaled by a factor of 100 .

\begin{tabular}{|c|c|c|c|c|c|c|c|c|c|}
\hline \multirow[b]{2}{*}{ Fixed effects ${ }^{*}$} & \multicolumn{3}{|c|}{ Emergence mass (g) } & \multicolumn{3}{|c|}{ Hind-foot length (mm) } & \multicolumn{3}{|c|}{ Growth until independence $(k)$} \\
\hline & Estimate \pm SE & $\mathrm{F}_{\mathrm{df}}$ & $p$-value & Effect \pm SE & $\mathrm{F}_{\mathrm{df}}$ & $p$-value & Effect \pm SE & $\mathrm{F}_{\mathrm{df}}$ & $p$-value \\
\hline Pup F & $-156.30 \pm 47.420$ & $9.273_{1,524}$ & $0.004^{\ddagger}$ & $-17.550 \pm 6.716$ & $7.031_{1,261}$ & 0.019 & $-7.57 \pm 2.089$ & $12.298_{1,625}$ & $0.002^{\ddagger}$ \\
\hline Pup age & $7.904 \pm 1.736$ & $40.989_{1,524}$ & $<0.001^{\ddagger}$ & $0.360 \pm 0.124$ & $4.620_{1,261}$ & $0.010^{\ddagger}$ & - & - & - \\
\hline Pup age $^{2}$ & $-0.118 \pm 0.033$ & $11.949_{1,524}$ & $0.002^{\ddagger}$ & $-0.001 \pm<0.001$ & 7.109 & $0.015^{*}$ & - & - & - \\
\hline Litter size & $-4.083 \pm 1.686$ & $0.265_{1,524}$ & 0.028 & NS & - & - & $-0.211 \pm 0.067$ & $0.625_{1,625}$ & $0.005^{\ddagger}$ \\
\hline Mother age & $-0.006 \pm 0.003$ & $0.734_{1,524}$ & $0.048^{\ddagger}$ & $-0.001 \pm<0.001$ & $4.682_{1,261}$ & $0.006^{*}$ & $-3.424^{*} 10^{-4} \pm 1.153^{*} 10^{-4}$ & $1.927_{1,625}$ & $0.008^{\ddagger}$ \\
\hline Mother mass & $0.097 \pm 0.031$ & $9.534_{1,524}$ & $0.007^{\ddagger}$ & $0.012 \pm 0.005$ & $7.276_{1,261}$ & $0.016^{\ddagger}$ & $4.804^{*} 10^{-3} \pm 1.363^{*} 10^{-3}$ & $12.399_{1,625}$ & $0.002^{\ddagger}$ \\
\hline Helper no. & $-1.145 \pm 0.327$ & $1.913_{1,524}$ & $0.003^{\ddagger}$ & NS & - & - & NS & - & - \\
\hline Lactator no. & $4.188 \pm 1.126$ & $11.848_{1,524}$ & $0.002^{\ddagger}$ & NS & - & - & $-0.100 \pm 0.046$ & $3.558_{1,625}$ & $0.042^{\ddagger}$ \\
\hline YOB & - & $3.084_{8,524}$ & - & - & $5.098_{5,261}$ & - & - & $6.549_{8,625}$ & - \\
\hline 2000 & $13.560 \pm 7.512$ & - & 0.090 & $0.162 \pm 1.281$ & - & 0.901 & $-0.064 \pm 0.326$ & - & 0.847 \\
\hline
\end{tabular}




\begin{tabular}{|c|c|c|c|c|c|c|c|c|c|}
\hline 2001 & $20.220 \pm 8.261$ & - & 0.026 & - & - & - & $-0.238 \pm 0.327$ & - & 0.476 \\
\hline 2002 & $7.852 \pm 8.316$ & - & 0.359 & - & - & - & $-0.196 \pm 0.310$ & - & 0.534 \\
\hline 2003 & $10.230 \pm 9.433$ & - & 0.294 & - & - & - & $-0.099 \pm 0.429$ & - & 0.819 \\
\hline 2004 & $9.247 \pm 7.312$ & - & 0.224 & $1.708 \pm 1.229$ & - & 0.184 & $-0.069 \pm 0.318$ & - & 0.832 \\
\hline 2005 & $5.583 \pm 7.412$ & - & 0.462 & $-0.839 \pm 1.135$ & - & 0.470 & $-0.582 \pm 0.324$ & - & 0.090 \\
\hline 2006 & $6.376 \pm 8.590$ & - & 0.469 & $0.210 \pm 1.235$ & - & 0.867 & $-0.721 \pm 0.363$ & - & 0.063 \\
\hline 2007 & $-8.209 \pm 12.790$ & - & 0.530 & $-1.479 \pm 1.871$ & - & 0.441 & $-1.922 \pm 0.592$ & - & 0.004 \\
\hline Season & - & - & - & $-1.707 \pm 0.613$ & $3.737_{1,261}$ & $0.001^{*}$ & - & - & - \\
\hline Rainfall & NS & - & - & $0.009 \pm 0.004$ & $2.037_{1,261}$ & $0.004^{\ddagger}$ & $0.036 \pm 7.476^{*} 10^{-4}$ & $14.496_{1,625}$ & $<0.001^{\ddagger}$ \\
\hline$F^{*}$ pup age & $-13.544 \pm 6.245$ & $4.672_{1,524}$ & 0.046 & - & - & - & NS & - & - \\
\hline$F^{*}$ pup age ${ }^{2}$ & $-0.321 \pm 0.122$ & $6.945_{1,524}$ & 0.018 & - & - & - & NS & - & - \\
\hline$F^{*}$ lactator no. & $-131.000 \pm 25.270$ & $26.857_{1,524}$ & $<0.001^{\ddagger}$ & - & - & - & $-3.638 \pm 1.135$ & $10.319_{1,625}$ & $0.005^{\ddagger}$ \\
\hline Random effects & & Variance & $\%$ & & Variance & $\%$ & & Variance & $\%$ \\
\hline Mother ID & & $<0.001$ & $<0.001$ & & $5.974^{*} 10^{-15}$ & $<0.001$ & & $8.313^{*} 10^{-14}$ & $<0.001$ \\
\hline Litter ID & & 373.240 & 66.333 & & 4.686 & 57.845 & & $7.840^{*} 10^{-4}$ & 58.289 \\
\hline Birth group ID & & 96.514 & 17.153 & & 0.000 & 0.000 & & $2.029 * 10^{-4}$ & 15.1082 \\
\hline Residual & & 92.925 & 16.515 & & 3.415 & 42.155 & & $3.582 * 10^{-4}$ & 26.629 \\
\hline
\end{tabular}

*NS variables not fitted in the final minimal model: pup sex; mother $F$; mother status; mother age ${ }^{2}$ and helper number ${ }^{2}$.

${ }^{\dagger}$ Reference level for pup year of birth is 1999.

$\$$ Significant after sequential Bonferroni correction. 
a.)

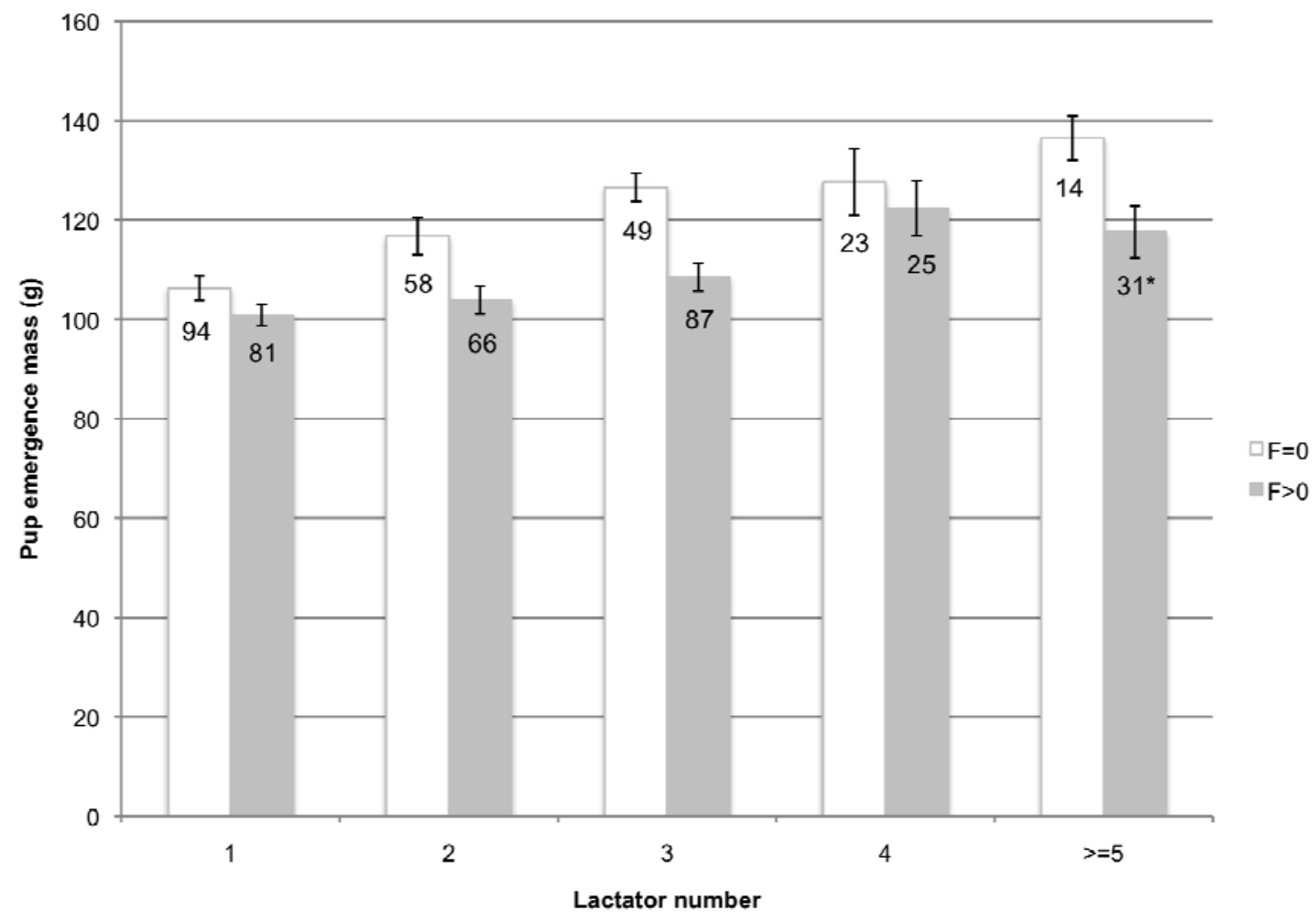


b.)

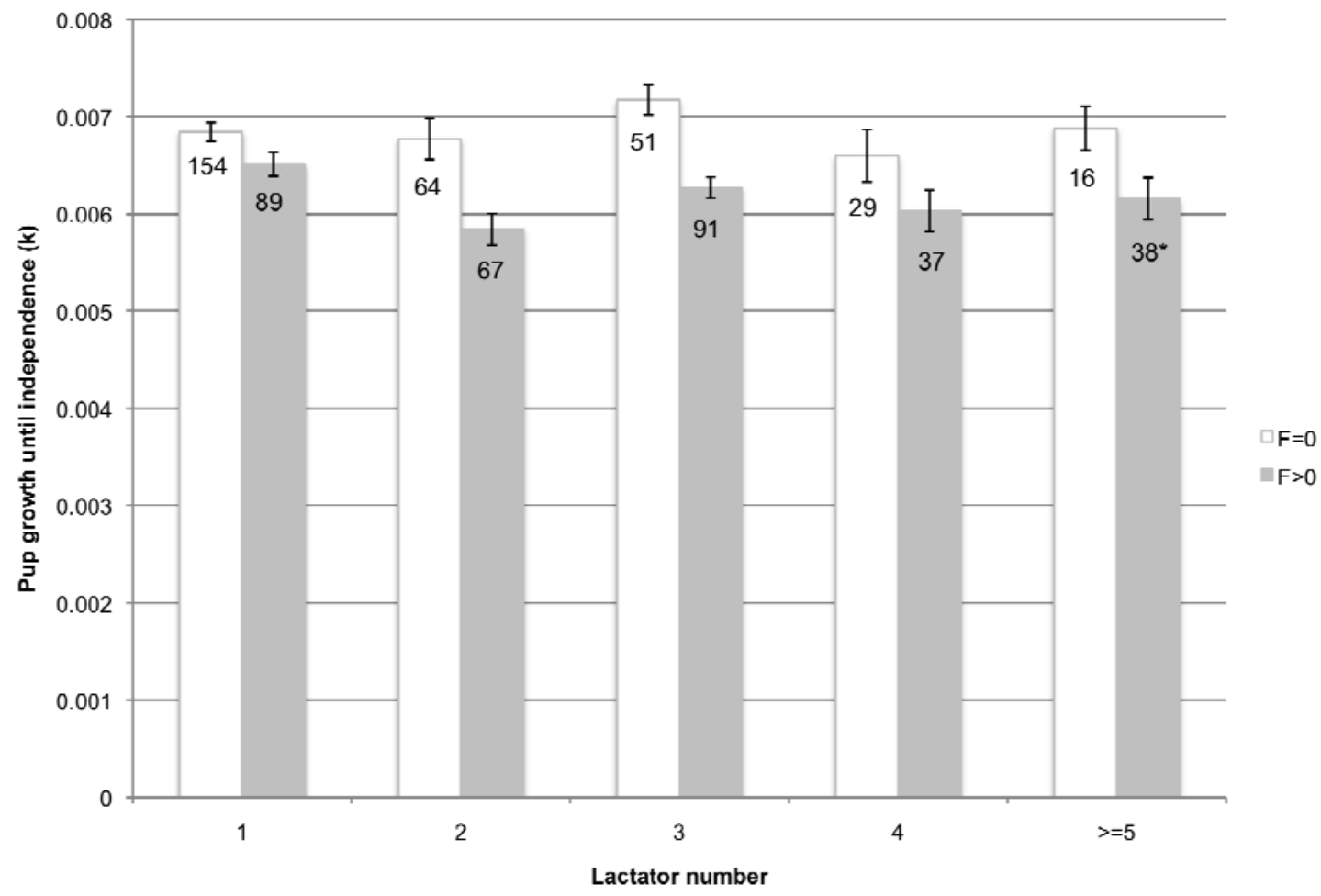

Fig. 4 The effect of lactator number on inbreeding depression in pup a.) emergence mass and b.) growth until independence. Sample sizes (number of pups) are given at the top of each bar. Increasing numbers of lactators increased emergence mass for both inbred and outbred pups with $\leq 4$ lactators whereas the mass of inbred pups was depressed with $\geq 5$ lactators. Inbred pups tended to grow more slowly with increasing numbers of lactators. Columns with asterisks include one large subordinate breeding event of 11 pups born to 5 different mothers and 8 lactators, which was removed in a subsequent analysis. 


\section{Growth until independence}

Growth until independence showed strong inbreeding depression (parameter estimate $=-7.57 \pm$ 2.089 S.E.) (Table $4 \&$ Fig. $3 c$ ). For an individual with $F=0.078$ this parameter estimate translates into an approximately $9.3 \%$ reduction in growth compared with individuals with $F=0$ and the negative effect of $F$ remained when $F>0.13$ values were removed (Fig. $3 c$ dashed line). Plotted raw data show that on average $F=0$ pups grew faster than $F>0$ pups (Fig. $4 b$ ). There was also a negative interaction between pup $F$ and lactator number (parameter estimate $=-3.64 \pm 1.14$ S.E.) (Table 4). In contrast to emergence mass, growth until independence was approximately constant regardless of lactator number for outbred pups $(F=0)$ whereas increasing lactator number was negatively associated with growth in inbred pups $(F>0)$ (Fig. $4 b)$, but as with emergence mass, the effects of inbreeding depression were stronger with large numbers of lactators. This interaction remained even when moderately inbred $(F \geq 0.125)$ individuals were excluded from the model but disappeared when one exceptionally large subordinate breeding event was removed. In contrast to emergence mass, the main effect of $F$ remained even when this breeding event was excluded from analysis.

\section{Survival}

Pup survival (from emergence to 90 days) did not show any evidence of inbreeding depression due to the fact that all the pups with high $F(n=37)$ in the data set survived this period of time (Table $5 \&$ Fig. 5a). Juvenile survival (from 90 to 180 days) showed evidence of inbreeding depression: Pup F was positively associated with hazard (parameter estimate $=11.573 \pm 4.405$ S.E.) such that, on average, individuals with $F=0.078$ were 2.46 $(\exp (11.573 * 0.078))$ times more likely to die than $F=0$ individuals (Table $5 \&$ Fig. $5 b$ ). Although we did not specifically test for effects of inbreeding on pup survival from birth to 
Table 5 Results of Cox proportional hazard survival analyses for pup survival (from emergence to 90 days; $n=561$ ) and juvenile survival (from 90 to 180 days; $n=497)$. The final minimal models were simplified where $-\left(\mathrm{AIC}_{\text {null }}-\mathrm{AIC}_{\text {model }}\right)$ was minimised. $\Delta \mathrm{AIC}$ gives the difference in AIC values between the final minimal models and a model including the term in question and the $p$-values give the significance of the term prior to its removal. The estimate of effects (and accompanying standard errors) refer to the effects on the proportional hazard rate and variables in bold are retained in the final minimal model. Litter ID was fitted as a random effect.

\begin{tabular}{|c|c|c|c|c|c|c|}
\hline \multirow[b]{2}{*}{ Fixed effects } & \multirow[b]{2}{*}{$\triangle \mathrm{AIC}$} & \multicolumn{2}{|l|}{ Pup survival } & \multicolumn{3}{|c|}{ Juvenile survival } \\
\hline & & Effect \pm SE & $p$-value & $\Delta \mathrm{AIC}$ & Effect \pm SE & $p$-value \\
\hline Sex & 2.21 & $0.232 \pm 0.293$ & 0.430 & 2.24 & $0.195 \pm 0.371$ & 0.600 \\
\hline Litter size & 0 & $-0.207 \pm 0.171$ & 0.220 & 0 & $0.263 \pm 0.202$ & 0.190 \\
\hline Mother age & 0.74 & $<0.001 \pm<0.001$ & 0.490 & 1,77 & $<0.001 \pm<0.001$ & 0.610 \\
\hline Mother mass & 0 & $-0.006 \pm 0.003$ & 0.038 & 0.1 & $0.004 \pm 0.004$ & 0.300 \\
\hline Helper no. & 1.32 & $0.001 \pm 0.026$ & 0.960 & 0 & $-0.064 \pm 0.032$ & 0.046 \\
\hline Lactator no. & 1.01 & $0.057 \pm 0.110$ & 0.600 & 0.86 & $-0.238 \pm 0.176$ & 0.180 \\
\hline Rainfall & 1.02 & $0.001 \pm 0.003$ & 0.630 & 0.68 & $0.003 \pm 0.004$ & 0.450 \\
\hline
\end{tabular}


a.)

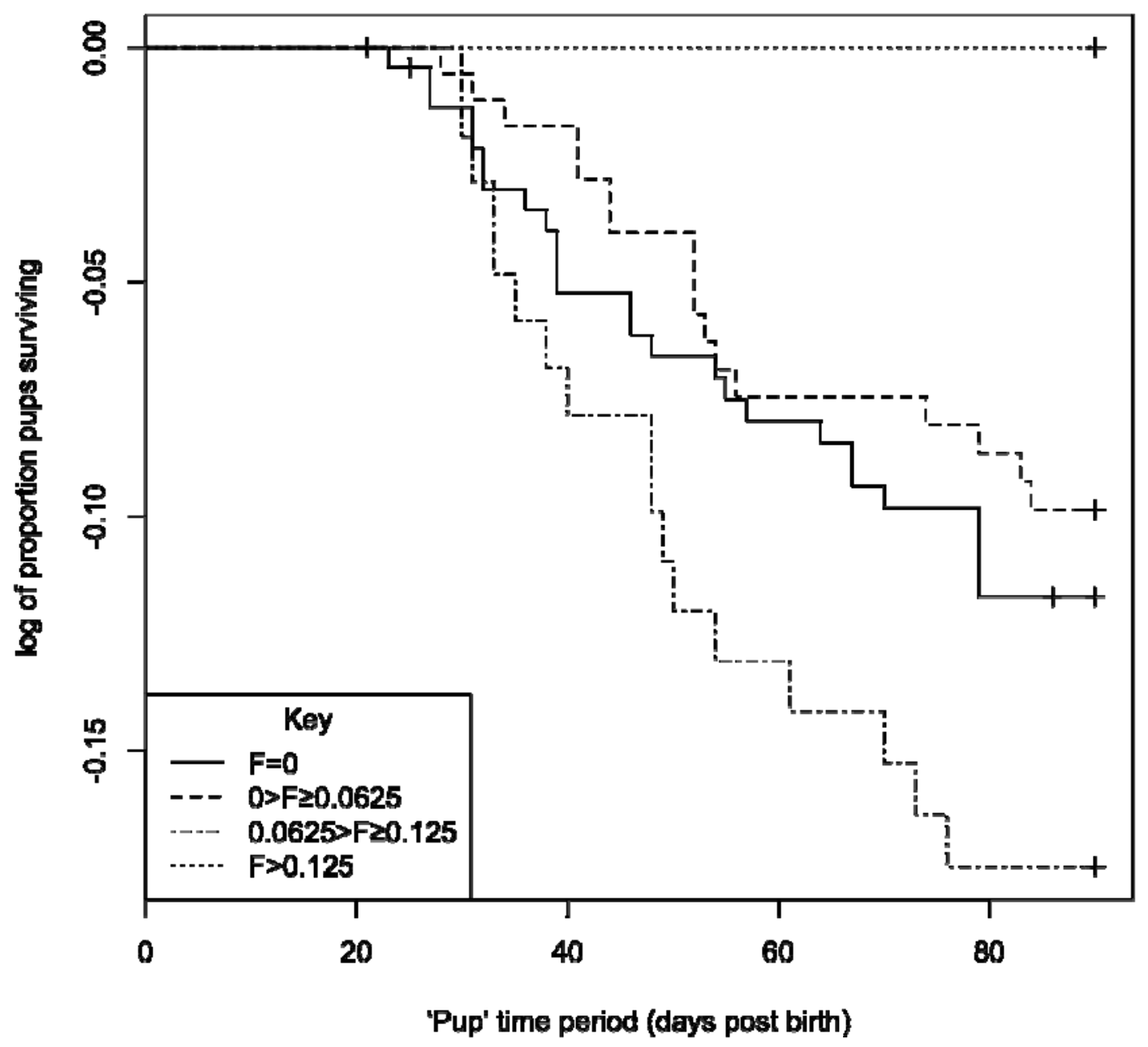


b.)

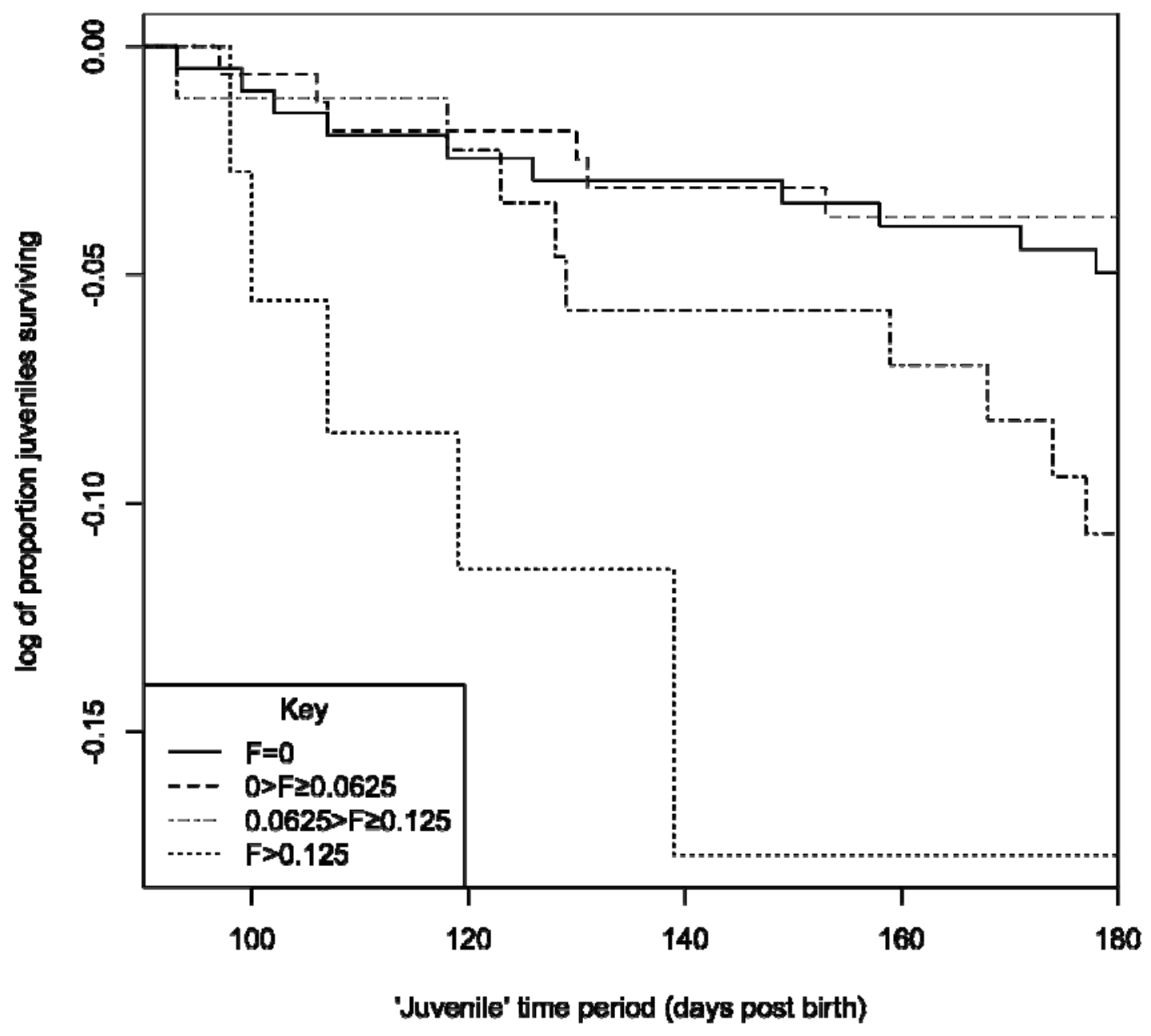

Fig. 5 Survival curves for $a$.) pup survival (emergence to 90 days) and $b$.) juvenile survival (90 to 180 days) for different $F$-value categories. All moderately inbred pups ( $F>0.125$; $n=37)$ survived the pup period, whereas the survival of outbred and lowly inbred $(F<0.125)$ pups was similar. The hazard rate for inbred individuals was greater in the juvenile time period: survival for $F=0$ or pups with low $F$ values were similar, with decreasing survival rates for moderately and highly inbred pups. 
emergence, a strong negative correlation between pup $F$ and litter size at emergence was detected (Supporting Table 4) suggesting that inbred pups suffer a higher rate of early neonatal mortality within the burrow.

\section{Role of other variables}

The other fitted variables had a variety of effects depending on the trait analysed. Pup age

had a significant positive effect and pup age ${ }^{2}$ had a significant negative effect on emergence mass and hind-foot length (Table 4). Litter size either had a significant negative effect (emergence mass \& growth until independence) or no effect (hind-foot length and survival) (Tables $4 \& 5$ ). Mother's age and mass had consistently negative and positive effects respectively on the emergence mass and the skeletal traits and no significant effect on juvenile survival (Tables $4 \& 5$ ). Mother's mass did however have a positive effect on survival from emergence to independence, i.e. it was negatively associated with hazard rate such that for each gram increase in a mother's mass (for pups of the same age) the risk of death was reduced to $0.994 \pm 0.038$ of the baseline hazard (Table 5). Helper number had a variable effect: it had a negative effect on emergence mass, no effect on hind-foot length and growth until independence, and a positive effect on juvenile survival, i.e. it was negatively associated with hazard rate such that for each unit increase in the number of helpers (for pups of the same age) the risk of death was reduced to $0.938 \pm 0.032$ of the baseline hazard (Table 5). Lactator number also had a variable effect: as reported above it positively influenced emergence mass, but it negatively affected growth until independence and had no effect on hind-foot length and the survival periods. Where significant, rainfall and season had positive (growth until independence \& hind-foot length) and negative (hind-foot length) effects respectively and had no effect on survival over either stage investigated. None of the other 
variables (pup sex, mother $F$, mother status, mother $\operatorname{age}^{2}$ and helper number ${ }^{2}$ ) had a significant effect on any of the traits.

Litter explained the overwhelming majority of the variance in emergence mass (66\%), hindfoot length (58\%) and growth until independence (58\%) whereas maternal effects were negligible $(<0.001 \%)$ (Table 4). Birth group explained some of the variance in emergence mass $(17 \%)$ and growth until independence $(15 \%)$ but not hind-foot length $(0 \%)$, and unexplained residual variance varied from $17 \%$ (emergence mass) to $42 \%$ (hind-foot length).

\section{Discussion}

We found that matings between relatively distant relatives resulted in approximately $44 \%$ of the study population of meerkats being inbred to some extent. Furthermore we found negative consequences of inbreeding for a range of morphometric and survival traits, which appear to be driven by pup rather than mother's inbreeding coefficients. We also found some evidence that social factors affect the expression of inbreeding depression. We discuss each of these in turn below.

\section{Occurrence of inbreeding}

The extent of inbreeding in the study population is generally much higher than that reported in other wild vertebrate systems (e.g. Keller \& Waller 2002; Richardson et al. 2004; RiouxPaquette et al. 2010; Schiegg et al. 2006; Szulkin \& Sheldon 2007; Walling et al. 2011). Furthermore, the fact that more than half of the breeding pairs in the study population are related, and that subordinates are statistically more likely than dominants to produce inbred offspring, indicates that inbreeding is widespread rather than being simply the result of a few 
highly productive, but inbreeding, dominant pairs. The extent and magnitude of inbreeding we report herein is likely to be an underestimate due to the fact that classical pedigree construction assumes that population founders and immigrants are unrelated and non-inbred, and because of the incompleteness of the reconstructed pedigree. Although the two study systems are very different, our results are somewhat comparable to those found using a social pedigree of a population of song sparrows where $44 \%$ of all matings were between known relatives (Keller 1998). Keller (1998) concluded that the high level of inbreeding in song sparrows was in part due to that fact that the Mandarte population of song sparrows lives on an isolated island where only $3 \%$ of the breeding birds were immigrants, creating a scenario where (related) residents are more likely to mate with each other. In contrast, a very different population scenario governs the Kalahari meerkat population studied herein: although individuals live in distinct groups which are characterised by a strong reproductive skews in favour of dominants, it is an open population and there are no distinct geographical barriers preventing individuals from outside the study population migrating into it (Clutton-Brock et al. 2002; Stephens et al. 2005). An additional similarity to the Mandarte song sparrow population (Keller 1998) is that the majority of meerkat consanguineous matings were between distantly related kin, rather than close relatives, which resulted in low to moderate $F$ values (average $F=0.078$ ). Perhaps more pertinent to meerkats, the levels of inbreeding we report here are most comparable to levels reported in a cooperative mammal population of black-tailed prairie dogs (Cynomys ludovicianus) in which $26 \%$ of all copulations were between kin $(0.2500>r \geq 0.0078)$ (Hoogland 1992). A study on a population of dwarf mongooses (Helogale parvula) also reported widespread moderate inbreeding but also reported that $14 \%$ of offspring resulted from matings between close relatives (Keane et al. 1996). It is worth noting that although Hoogland (1992) tested for (but did not find evidence 
of) inbreeding depression, neither the Hoogland (1992) nor the Keane et al. (1996) data was supported by genetics.

\section{Evidence for inbreeding depression}

We found evidence for negative consequences of inbreeding, driven by pup's $F$ rather than mother's $F$, for a range of early life traits. Mating between relatively distant meerkat kin and their ancestors appeared sufficient to cause inbreeding depression as the negative effects of inbreeding remained even when high values of $F(F>0.13)$ were removed, suggesting that inbreeding depression was not driven by extreme inbreeding events. Similarly, a recent study that found that inbreeding in red deer was not dominated by close inbreeding events and that inbreeding depression was not solely driven by individuals with high $F$-values (Walling et al. 2011).

Inbreeding depression was evident for emergence mass, hind-foot length and growth until independence. Previous studies in wild mammalian populations have also reported inbreeding depression in early weight measures (e.g. Coltman et al. 1998; Coulson et al. 1998; Slate \& Pemberton 2002; Walling et al. 2011). We also found evidence for inbreeding depression in hind-foot length. Although the other two skeletal measures (skull length and forearm length) showed no evidence for inbreeding depression, all the skeletal measures had small sample sizes and may suffer more from measurement error and consequently our analyses here probably suffered from a lack of power. As the skeletal measures were highly correlated, we predict that larger samples sizes would reveal similar patterns of inbreeding depression in these traits. To the best of our knowledge this is the first study that has investigated the effects of inbreeding on early life growth rates in a wild population of 
mammals. As weight has been shown to have positive consequences for both fitness and dominance in meerkats (Hodge et al. 2008; Russell et al. 2002) it follows that a low growth rate due to inbreeding is likely to be disadvantageous in terms of fitness.

There was evidence of inbreeding depression on juvenile survival, but none for pup survival, suggesting that the strong inbreeding depression on emergence mass, hindfooot length and growth until independence did not translate into survival costs until after pups reached independence. Upon reaching independence, helpers discontinue provisioning pups and the juveniles must provide for themselves, although they may continue to receive benefits from group living such as greater protection from predators and neighbouring meerkat groups (Clutton-Brock et al. 1999a). Reaching independence may therefore represent a 'stressful' environment in which the consequences of inbreeding depression are more pronounced. Previous investigations of environmental effects on inbreeding depression have demonstrated a general pattern of increased inbreeding depression under more stressful environments (Fox \& Reed 2011; Keller et al. 2002; Marr et al. 2006; Szulkin \& Sheldon 2007). Our results provide some evidence that the stress imposed by a change in social environment (the discontinuation of helper provisioning for post-independence meerkats) is analogous to the ecologically stressful environments reported in other animal populations. Put another way, it is possible that helpers 'buffer' pups from the effects of inbreeding prior to independence.

It is worth noting that in all these analyses, data was only collected from pups that emerged from their natal burrow. It is therefore possible that pups that suffered from such severe inbreeding depression that they died prior to emergence were excluded. Although the study system prevents us from explicitly testing whether entire litters failed to emerge, the fact that 
litter size was negatively associated with pup $F$ suggests that inbred pups may be more likely to suffer a higher rate of early neonatal mortality within the burrow and provides further evidence for inbreeding depression in this system.

\section{Interactions between inbreeding depression and other traits}

The general positive effect of lactator number on emergence mass provides some evidence that the social environment (allolactators) can, to some extent, buffer (but not completely compensate) inbred pups from the negative effects of inbreeding. This is consistent with the findings of Russell et al. (2002) who found that subordinate helping positively influences the weight, survival and daily weight gain of pups. The negative interaction of pup $F$ with emergence weight and growth until independence, in which increased lactator numbers had increasingly negative effects on more inbred pups, is more difficult to interpret. As we found that inbred pups were more likely to be born to subordinate females and because subordinates are more likely to give birth into 'mixed litters' composed of other (subordinate or dominant) pups of the same age (M. Bell, pers. comm.), we speculate that the negative interaction with allolactation may reflect greater competition between pups and the relative failure of inbred pups to 'win' allolactator's milk. Re-analysis of our data following the removal of one exceptionally large subordinate breeding event in a group with many lactators suggests that mixed litter, subordinate inbreeding may indeed be driving much of the pup $F \mathrm{x}$ lactator number interactions. Given that we have found that subordinates are more likely than dominants to produce inbred pups, but that dominants are responsible for the majority of the total breeding in the population, we believe it is not appropriate to simply interpret the results with this mixed litter excluded. An alternative possibility is that our measure of lactator number is an overestimate of true allolaction provisioning in this instance. 


\section{Effects of other variables}

Maternal, social and environmental variables influenced the variance of traits in different ways. All pre-independence traits showing evidence for inbreeding depression were positively affected by mother's conception mass and negatively affected by mother's age, indicating either that maternal condition is an important early life factor in this cooperativelybreeding species (Russell \& Lummaa 2009), that conception mass is heritable and/or that it is positively genetically correlated with the traits presented here. Social factors had opposing influences during this period: helper number was either non-significant or had a negative effect whereas the number of lactators had largely positive effects. Previous research in the population has found that social factors, such as subordinate helping, positively influences the weight and survival of pups and concluded that, to some extent, they replace the importance of maternal factors (Clutton-Brock et al. 2002). By including lactator number as a separate variable in our analyses we were able to apportion some of this positive effect of helping to a specific helper type during the pre-foraging period, although this variable had complex interacting effects (see above). A previous study on the same population found that pup daily weight gain was positively influenced by the number of helpers per pup and rainfall (which positively influences invertebrate abundance), and negatively influenced by daytime temperature (Clutton-Brock et al. 2002). Although we found that accumulated rainfall in the last three months was positively associated with pup growth-rate, we found no effect of total helper number and a weak negative effect of lactator number, though it is worth noting that Russell et al. 2002 used a slightly different index of helper availability than we have here. During the juvenile period helper number decreased the hazard risk which is in line with previous research that demonstrated a positive effect of increased group size (Russell et al. 2002). Maternal effects explained very little of the variance in our models so it is perhaps not 
surprising that mother's $F$ did not have an important effect on pup traits, but given the highly social nature of meerkats and that previous research has demonstrated positive effects of helper number, one interesting line of research would be to test whether there is an association between $F$ and the amount of care contributed by helpers.

Since the traits investigated herein are proxies for total fitness (see introduction), future work should investigate the effect of inbreeding on reproductive success and/or on later-life survival periods. Due to the substantial rate of mortality and reproductive skew in meerkats, these analyses require rather larger sample sizes than is currently available.

\section{Evolution of inbreeding avoidance}

Inbreeding depression effects are likely to generate strong selective pressures for inbreeding avoidance behaviours (Waser et al. 1986). Given that we have shown that low-moderate inbreeding leads to substantial negative consequences, why has a more reliable inbreeding avoidance mechanism not evolved in meerkats? One possibility is that moderate inbreeding is tolerated because the benefits of inbreeding outweigh the costs of inbreeding depression (Kokko \& Ots 2006; Waser et al. 1986). Our results show that subordinates are more likely than dominants to produce inbred pups. In meerkats, where the vast majority of reproductive events are monopolised by the dominant pair, subordinate females are primarily limited to mating with immigrant or roving males, who are typically also subordinates (Griffin et al. 2003). The high costs of dispersal (Young et al. 2005) places relatives in close proximity to each other and consanguineous matings may represent the only opportunities for reproduction that subordinates will gain. As any subordinate mating opportunity is better than none, there may not be strong selection on discriminating the fine-scale relatedness of mates. 
We speculate that experience of relatives early in life may be the main source of information on which meerkats base inbreeding avoidance, as we found that much of the inbreeding in the population came about via matings among reasonably distant kin and that the vast majority of matings resulting in $F>0.125$ were between relatives from different natal groups. Similarly, Hoogland (1992) reported that prairie dogs appear to avoid extreme inbreeding as only $5 \%$ of all copulations involved a sexual partner of $r \geq 0.25$. Our findings support the hypothesis that male-biased dispersal and lack of intra-group matings between natal members may act as an effective way of avoiding mating between closely related meerkat kin (Griffin et al. 2003). The existence of mechanisms for avoiding matings between less closely related kin (e.g. cousins) is less convincing. Sex-biased dispersal may have the effect of reducing the specialisation required to recognise kin in order to avoid inbreeding by limiting the rule of kin discrimination to those members an individual is familiar with i.e. natal or current group members (Koenig \& Haydock 2004). But as patterns of meerkat dispersal and male roving can be complicated, it is possible that kin born to neighbouring groups can immigrate or rove into a group and mate with relatives that they have had no previous contact with and thus do not 'recognise' as kin. In this way inbreeding occurs, which we have shown leads to inbreeding depression. Testing whether meerkats are indeed avoiding mating with kin and, if so, further determining the mechanisms they utilise to recognise relatives will be an important future line of research (Jordan et al. 2007; Mares et al. 2011).

\section{Acknowledgments}

We thank all the many volunteers and staff at the Kuruman River Reserve for the data collection and project management, the Kotze family for permission to work on their land and the Northern Cape Conservation Authority for allowing us to conduct research in the 
Kalahari. We would also like to thank Jarrod Hadfield for his help with MASTERBAYES,

Sheena Morrissey for genotyping assistance, Liz Heap for independently checking all the genotypes and Matt Bell, Michael Morrissey and the reviewers for their comments on an earlier version of this manuscript. The Meerkat project is funded by the Natural Environment Research Council and the Earthwatch Institute. JFN is funded by a NERC CASE studentship with the Institute of Zoology, London.

\section{References}

Bateman AW, Coulson T, Clutton-Brock TH (2011) What do simple models reveal about the population dynamics of a cooperatively breeding species? Oikos 120, 787-794.

Brown JL, Brown ER (1998) Are inbred offspring less fit? Survival in a natural population of Mexican jays. Behavioural Ecology 9, 60-63.

Clutton-Brock T (2002) Breeding Together: Kin Selection and Mutualism in Cooperative Vertebrates. Science 296, 69-72.

Clutton-Brock TH, Brotherton PNM, Smith R, et al. (1998) Infanticide and expulsion of females in a cooperative mammal. Proceedings of the Royal Society B: Biological Sciences 265, 2291-2295.

Clutton-Brock TH, Gaynor D, McIlrath GM, et al. (1999a) Predation, Group Size and Mortality in a Cooperative Mongoose, Suricata suricatta. Journal of Animal Ecology 68, 672-683.

Clutton-Brock TH, Maccoll A, Chadwick P, et al. (1999b) Reproduction and survival of suricates (Suricata suricatta) in the southern Kalahari. African Journal of Ecology 37, 69-80.

Clutton-Brock TH, Russell AF, Sharpe LL (2003) Meerkat helpers do not specialize in particular activities. Animal Behaviour 66, 531-540.

Clutton-Brock TH, Russell AF, Sharpe LL (2004) Behavioural tactics of breeders in cooperative meerkats. Animal Behaviour 68, 1029-1040.

Clutton-Brock TH, Russell AF, Sharpe LL, et al. (2001) Effects of Helpers on Juvenile Development and Survival in Meerkats. Science 293, 2446-2449.

Clutton-Brock TH, Russell AF, Sharpe LL, et al. (2002) Evolution and Development of Sex Differences in Cooperative Behavior in Meerkats. Science 297, 253-256.

Coltman DW, Bowen WD, Wright JM (1998) Birth weight and neonatal survival of harbour seal pups are positively correlated with genetic variation measured by microsatellites. Proceedings of the Royal Society B: Biological Sciences 265, 803-809.

Coulson TN, Pemberton JM, Albon SD, et al. (1998) Microsatellites reveal heterosis in red deer. Proceedings of the Royal Society B: Biological Sciences 265, 489-495.

Crawley MJ (2007) The R Book John Wiley, New York

Crnokrak P, Roff DA (1999) Inbreeding depression in the wild. Heredity 83, 260-270.

Daniels SJ, Walters JR (2000) Inbreeding Depression and Its Effects on Natal Dispersal in Red-Cockaded Woodpeckers. The Condor 102, 482-491. 
Dmitriew CM (2011) The evolution of growth trajectories: what limits growth rate? . Biological Reviews 86, 97-116.

Doolan SP, Macdonald DW (1999) Co-operative Rearing by Slender-tailed Meerkats "Suricata suricatta" in the Southern Kalahari. Ethology 105, 851-866.

English S, Bateman A, Clutton-Brock T (in press) Lifetime growth in wild meerkats: incorporating life history and environmental factors into a standard growth model. Oecologia.

Fox CW, Reed DH (2011) Inbreeding depression increases with environmental stress: an experimental study and meta-analysis. Evolution 65, 246-258.

Gaillard J-M, Pontier D, Allaine D, et al. (1997) Variation in Growth Form and Precocity at Birth in Eutherian Mammals. Proceedings of the Royal Society B: Biological Sciences 264, 859-868.

Griffin AS, Pemberton JM, Brotherton PNM, et al. (2003) A genetic analysis of breeding success in the cooperative meerkat (Suricata suricatta). Behavioural Ecology 14, 472480.

Griffin AS, West SA (2003) Kin Discrimination and the Benefit of Helping in Cooperatively Breeding Vertebrates. Science 302, 634-636.

Hadfield JD, Richardson DS, Burke T (2006) Towards unbiased parentage assignment: combining genetic, behavioural and spatial data in a Bayesian framework. Molecular Ecology 15, 3715-3730.

Hamilton WD (1963) The Evolution of Altruistic Behavior. The American Naturalist 97, 354356.

Hodge SJ, Manica A, Flower TP, Clutton-Brock TH (2008) Determinants of reproductive success in dominant female meerkats. Journal of Animal Ecology 77, 92-102.

Hoogland JL (1992) Levels of Inbreeding Among Prairie Dogs. The American Naturalist 139, 591-602.

Jennions MD, Macdonald DW (1994) Cooperative breeding in mammals. Trends in Ecology \& Evolution 9, 89-93.

Jordan NR, Cherry MI, Manser MB (2007) Latrine distribution and patterns of use by wild meerkats: implications for territory and mate defence. Animal Behaviour 73, 613-622.

Keane B, Creel SR, Waser PM (1996) No evidence of inbreeding avoidance or inbreeding depression in a social carnivore. Behavioural Ecology 7, 480-489.

Keller LF (1998) Inbreeding and Its Fitness Effects in an Insular Population of Song Sparrows (Melospiza melodia). Evolution 52, 240-250.

Keller LF, Arcese P, Smith JNM, Hochachka WM, Stearns SC (1994) Selection against inbred song sparrows during a natural population bottleneck. Nature 372, 356-357.

Keller LF, Grant PR, Grant RB, Petren K (2002) Environmental conditions affect the magnitude of inbreeding depression in survival of Darwin's finches. Evolution 56, 1229-1239.

Keller LF, Waller DM (2002) Inbreeding effects in wild populations. Trends in Ecology \& Evolution 17, 230-241.

Kinghorn BP (1994) Pedigree Viewer - a graphical utility for browsing pedigreed data sets. , 85-86.

Koenig WD, Haydock J (2004) Incest and incest avoidance. In: Ecology and Evolution of Cooperative Breeding in Birds (eds. Koenig WD, Dickenson JL), pp. 142-156. Cambridge University Press, Cambridge.

Kokko H, Ekman J (2002) Delayed Dispersal as a Route to Breeding: Territorial Inheritance, Safe Havens, and Ecological Constraints. The American Naturalist 160, 468-484. 
Kokko H, Ots I (2006) When not to avoid inbreeding. Evolution 60, 467-475.

Komdeur J (1992) Importance of habitat saturation and territory quality for evolution of cooperative breeding in the Seychelles warbler. Nature 358, 493 - 495.

Kruuk LEB, Sheldon BC, Merilä J (2002) Severe inbreeding depression in collared flycatchers (Ficedula albicollis). Proceedings of the Royal Society B: Biological Sciences 269, 1581-1589.

Lynch M, Walsh B (1998) Genetics and Analysis of Quantitative Traits Sinauer Associates, Inc., Sunderland, Massachusetts.

Mares R, Young AJ, Levesque DL, Harrison N, Clutton-Brock TH (2011) Responses to intruder scents in the cooperatively breeding meerkat: sex and social status differences and temporal variation. Behavioral Ecology 22, 594-600.

Marr AB, Arcese P, Hochachka WM, Reid JM, Keller LF (2006) Interactive effects of environmental stress and inbreeding on reproductive traits in a wild bird population. Journal of Animal Ecology 75, 1406-1415.

Marshall TC, Coltman DW, Pemberton JM, et al. (2002) Estimating the prevalence of inbreeding from incomplete pedigrees. Proceedings of the Royal Society B: Biological Sciences 269, 1533-1539.

McRae SB (1996) Family values: costs and benefits of communal nesting in the moorhen. Animal Behaviour 52, 225-245.

McRae SB, Amos W (1999) Can Incest within Cooperative Breeding Groups Be Detected Using DNA Fingerprinting? Behavioral Ecology and Sociobiology 47, 104-107.

Morrissey MB, Wilson AJ (2010) PEDANTICS: an r package for pedigree-based genetic simulation and pedigree manipulation, characterization and viewing. Molecular Ecology Resources 10, 711-719.

Nichols HJ, Amos W, Cant MA, Bell MBV, Hodge SJ (2010) Top males gain high reproductive success by guarding more successful females in a cooperatively breeding mongoose. Animal Behaviour 80, 649-657.

Pemberton JM (2008) Wild pedigrees: the way forward. Proceedings of the Royal Society B: Biological Sciences 275, 613-621.

Pusey A, Wolf M (1996) Inbreeding avoidance in animals. Trends in Ecology and Evolution 11, 201-206.

Rice WR (1989) Analyzing Tables of Statistical Tests. Evolution 43, 223-225.

Richardson DS, Komdeur J, Burke T (2004) Inbreeding in the Seychelles warbler: environment-dependent maternal effects. Evolution 58, 2037-2048.

Rioux-Paquette E, Festa-Biancheta M, Coltman DW (2010) Sex-differential effects of inbreeding on overwinter survival, birth date and mass of bighorn lambs. Journal of Evolutionary Biology 24, 121-131.

Rossiter SJ, Ransome RD, Faulkes CG, Le Comber SC, Jones G (2005) Mate fidelity and intra-lineage polygyny in greater horseshoe bats. Nature 437, 408-411.

Russell AF, Brotherton PNM, McIlrath GM, Sharpe LL, Clutton-Brock TH (2003) Breeding success in cooperative meerkats: effects of helper number and maternal state. Behavioral Ecology 14, 486-492.

Russell AF, Clutton-Brock TH, Brotherton PNM, et al. (2002) Factors affecting pup growth and survival in co-operatively breeding meerkats Suricata suricatta. Journal of Animal Ecology 71, 700-709.

Russell AF, Langmore NE, Cockburn A, Astheimer LB, Kilner RM (2007a) Reduced Egg Investment Can Conceal Helper Effects in Cooperatively Breeding Birds. Science 317, 941-944. 
Russell AF, Lummaa V (2009) Maternal effects in cooperative breeders: from hymenopterans to humans. Philosophical Transactions of the Royal Society B: Biological Sciences 27, 1143-1167.

Russell AF, Young AJ, Spong G, Jordan NR, Clutton-Brock TH (2007b) Helpers increase the reproductive potential of offspring in cooperative meerkats. Proceedings of the Royal Society B: Biological Sciences 274, 513-520.

Scantlebury M, Russell AF, McIlrath GM, Speakman JR, Clutton-Brock TH (2002) The energetics of lactation in cooperatively breeding meerkats Suricata suricatta. Proceedings of the Royal Society B: Biological Sciences 269, 2147-2153.

Schiegg K, Danielsa SJ, Waltersa JR, Priddyc JA, Pasinellia G (2006) Inbreeding in redcockaded woodpeckers: Effects of natal dispersal distance and territory location. Biological Conservation 131, 544-552.

Sharp SP, Clutton-Brock TH (2010) Reproductive senescence in a cooperatively breeding mammal. Journal of Animal Ecology 79, 176-183.

Slate J, Pemberton JM (2002) Comparing molecular measures for detecting inbreeding depression. Journal of Evolutionary Biology 15, 20-31.

Solomon NG (2003) A Reexamination of Factors Influencing Philopatry in Rodents. Journal of Mammalogy 84, 1182-1197.

Spiering PA, Gunther MS, Somers MJ, et al. (2011) Inbreeding, heterozygosity and fitness in a reintroduced population of endangered African wild dogs (Lycaon pictus). Conservation Genetics 12, 401-412.

Spong GF, Hodge SJ, Young AJ, Clutton-Brock TH (2008) Factors affecting the reproductive success of dominant male meerkats. Molecular Ecology 17, 2287-2299.

Stephens PA, Russell AF, Young AJ, Sutherland WJ, Clutton-Brock TH (2005) Dispersal, Eviction, and Conflict in Meerkats (Suricata suricatta): An Evolutionarily Stable Strategy Model. The American Naturalist 165, 120-135.

Szulkin M, Sheldon BC (2007) The Environmental Dependence of Inbreeding Depression in a Wild Bird Population. PLoS Biology 2, 1-7.

Szulkin M, Sheldon BC (2008) Dispersal as a means of inbreeding avoidance in a wild bird population. Proceedings of the Royal Society B: Biological Sciences 275, 703-711.

Taylor SS, Sardell RJ, Reid JM, et al. (2010) Inbreeding coefficient and heterozygosityfitness correlations in unhatched and hatched song sparrow nestmates. Molecular Ecology 19, 4454-4461.

Thompson EA (1976) A Paradox of Genealogical Inference. Advances in Applied Probability 8, 648-650.

Thompson EA, Meagher TR (1987) Parental and Sib Likelihoods in Genealogy Reconstruction. Biometrics 43, 585-600.

Thornton A, McAuliffe K (2006) Teaching in Wild Meerkats. Science 313, 227-229.

Walling CA, Nussey DH, Morris A, et al. (2011) Inbreeding depression in red deer calves. BMC Evolutionary Biology 11.

Wang J (2004) Sibship Reconstruction From Genetic Data With Typing Errors. Genetics 166, 1963-1979.

Wang J, Santure AW (2009) Parentage and Sibship Inference From Multi-locus Genotype Data Under Polygamy. Genetics 181, 1579-1594.

Waser PM, Austad SN, Keane B (1986) When Should Animals Tolerate Inbreeding? The American Naturalist 128, 529-537.

West SA, Pen I, Griffin AS (2002) Cooperation and Competition Between Relatives. Science 296, 72-75. 
Young AJ, Carlson AA, Clutton-Brock T (2005) Trade-offs between extraterritorial prospecting and helping in a cooperative mammal. Animal Behaviour 70, 829-837. 


\section{Supporting Information}

\section{DNA extraction}

Immediately after collection, tissue samples were stored in microcentrifuge tubes containing either $100 \mathrm{mM}$ EDTA $95 \%$ ethanol or $10 \%$ DMSO in saturated salt and kept in a $-20^{\circ} \mathrm{C}$ freezer at the field site before being transported to Europe for processing. Genomic DNA was extracted from the 2002 to 2009 tissue samples using a DNeasy Blood and Tissue Kit ${ }^{\mathrm{TM}}$ (QIAGEN) following slightly optimised manufacturer's instructions. Samples that were collected prior to 2002 were extracted either using a DNeasy Blood and Tissue $\mathrm{Kit}^{\mathrm{TM}}$, standard chelex (Spong et al. 2008) or phenol-chloroform methods (Griffin et al. 2003; Spong et al. 2008).

\section{Genotyping}

All loci that had previously been successfully amplified in meerkats (Griffin et al. 2001; Spong et al. 2008) were tested and optimised for multiplex amplification and 18 of the 25 potential loci were used in the final multiplex and co-loaded reactions. Primer pairs that only weakly amplified target microsatellite loci and/or that generated strong background products within the allele peak range were redesigned manually and labelled with different fluorescent labels (6-FAM, VIC, NED or PET (ABI)) (Supporting Table 1). Final multiplex PCR reactions consisted of the following: 20-50ng of DNA, 1.5x $\mathrm{NH}_{4}$ buffer, $0.2 \mathrm{mM}$ dNTPs, 1.5mM $\mathrm{MgCl}_{2}, 0.07-0.41 \mu \mathrm{M}$ of each primer, $0.0 .25 \mathrm{U} / \mu \mathrm{L}$ of Taq polymerase and double processed tissue culture distilled $\mathrm{H}_{2} \mathrm{O}$ (Sigma) to bring the volume up to $10 \mu \mathrm{L}$ (Supporting Table 1). PCR procedures involved an initial denaturation step of $95^{\circ} \mathrm{C}$ for 3 minutes, a threestep cycle consisting of denaturation at $94^{\circ} \mathrm{C}$ for 30 seconds, annealing at 58 or $60^{\circ} \mathrm{C}$ for 1 
minute, ramping at $0.3^{\circ} \mathrm{C} /$ second to an extension step of $72^{\circ} \mathrm{C}$ for 1 minute. This cycle was repeated 29 times and was followed by a final extension of $60^{\circ} \mathrm{C}$ for 15 minutes. Multiplex PCR products were diluted between $1: 7$ and 1:16 in $\mathrm{H}_{2} \mathrm{O}$ and $1 \mathrm{uL}$ of this diluted product was mixed with $9 \mu \mathrm{L}$ of loading mix $\left(1 \mathrm{~mL}\right.$ Hi-Di ${ }^{\mathrm{TM}}$ Formamide and $1 \mu \mathrm{L}$ of Genescan LIZ 500 ladder (ABI)) before being run in a capillary ABI 3730 DNA Analyzer. Loci that were not amenable to multiplex PCR amplification were amplified in uniplex following slightly modified reaction and cycling conditions: $\mathrm{MgCl}_{2}$ concentration increased to $2.5 \mathrm{M}$, initial denaturation reduced to 1 minute and annealing temperatures variably reduced (Supporting Table 2). Uniplex products were then diluted and mixed together to form a co-loaded set prior to being run on an ABI 3730 DNA Analyzer. The GeneMapper (v.4.0) analysis software was used to detect and score allele sizes and any samples with ambiguous alleles or failed amplifications were re-genotyped in single PCR reactions. All individual genotypes were scored and independently checked at least twice. A total of 1,494 individuals (96\% of the sampled population were genotyped at one or more locus. On average 17 loci were genotyped per individual: 1,234 individuals (83\% of the genotyped population) had complete genotypes for all 18 microsatellite loci and 1,454 (97\% of the genotyped population) had at least nine loci genotyped.

The mean number of alleles per locus, allele frequencies, expected $\left(H_{E}\right)$ and observed $\left(H_{O}\right)$ heterozygosities, deviations from Hardy-Weinberg (H-W) equilibrium, the probability of excluding a parent at a locus in the absence of genotype information of the parent $\left(N E_{-1 p}\right)$ and null allele frequency estimates were calculated in CERVUS 3.0.3 (Marshall et al. 1998) (Supporting Table 2). Although 13 loci showed deviations from $\mathrm{H}-\mathrm{W}$ equilibrium prior to Bonferroni correction, simulations have shown that violation of $\mathrm{H}-\mathrm{W}$ equilibrium has only 
minor effects of the accuracy of subsequent parentage inference analyses (Wang \& Santure 2009). Furthermore, the relatively small deviations from $\mathrm{H}-\mathrm{W}$ equilibrium reported herein are most likely due to the fact the sample sizes are large. Per locus genotyping error rates were manually calculated from the proportion of mismatching genotypes for any samples that were genotyped two or more times (Supporting Table 2). These values provide an upper estimate of error as generally only difficult samples were re-genotyped. In the subsequent CoLONY2 parentage analyses half of this error rate was attributed to allelic dropout (class I error) and the other half to all other kinds of stochastic typing errors (class II error) (Wang 2004).

\section{Parentage inference}

Familial relationships were inferred using COLONY2 version 2.0.1.1

(http://www.zsl.org/science/research/software/colony,1154,AR.html) (Wang 2004; Wang \& Santure 2009) and MASTERBAYES version 2.47 (http://cran.rproject.org/web/packages/MasterBayes/index.html) (Hadfield et al. 2006), which was implemented in R version 2.10.1 (R Development Core Team 2009). All individuals genotyped at any loci were included in the pedigree recovery analyses as both programs can make use of incomplete information.

\section{COLONY2}

Only genotyped pups and putative parents were included in the COLONY2 analyses and each pup born during the study period had between 2 and 642 (mean=100) known candidate fathers. Only best maximum likelihood parentage assignments with at least $80 \%$ individuallevel confidence were accepted in the final combination of program results. Where 'dummy' mothers were assigned (i.e. if maternity was assigned to an ungenotyped female), maternity 
was attributed to the identity of the ungenotyped candidate mother if the pup had more than one candidate mother and the other candidate(s) were genotyped (and therefore assignable). Some 'dummy' paternal identities could be attributed to a known ungenotyped candidate father by further investigation into the life histories of the candidate males (i.e. by considering if the dominant male was ungenotyped or by further restricting candidate father lists to those males either resident in, or known to have roved to, the pup’s natal group within the conception window).

A second COLONY2 analysis was run in an attempt to see if any sibships could be recovered among founders and immigrants to the population (who lack early life history data) without attempting to infer parentage. The CERvus3.0.3 (Marshall et al. 1998) Identity Analysis function was used to check whether any of the inferred 'dummy' parent genotypes resulting from this analysis matched any of the genotypes in the entire genotypic dataset.

\section{MASTERBAYES}

All individuals were included in the MASTERBAYES model with each individual attributed an identifier as to whether or not it was a pup, and thus required parental assignment, or a potential parent in any given month throughout the entire duration of the project. Confidence in an individual assignment was calculated as the proportion of iterations for which an individual was assigned parentage of a particular pup. A categorical pedigree was generated from this model in which only assignments with at least $80 \%$ individual-level confidence were considered in the final combination of program results.

The majority of MASTERBAYES and COLONY2 inferred maternities (94\%) and paternities 
(92\%) matched. Where mismatches occurred priority was given to COLONY2 inferences. This was based on the fact that COLONY2 inferred more parents than MASTERBAYES and accurately determined more correct maternities in trial runs where maternal identity was known but this information was not provided to either program. Furthermore, when certain genotyped fathers were excluded from trial CoLONY2 runs, the inferred genotype of the unsampled 'dummy' fathers assigned to the sibship in question matched the genotype of the assigned (true) father in subsequent analyses when all genotyped candidate fathers were included. MASTERBAYES assignments were however additionally informative in the few instances where it appeared that COLONY2 had either split true half-sib groups, assigning some half-sibs the correct genotyped parent and the other half-sibs an unsampled 'dummy' parent, or assigned complete half-sib groups but failed to confidently assign the correct genotyped parent (Walling et al. 2010). In these cases MASTERBAYES assignments, used in conjunction with detailed comparisons of the true and the COLONY2 inferred 'dummy' parent genotypes and re-analysis of these sib ships, resulted in the final assignment of the sampled parent. The parentage assignments from the two programs were compared and summarised following Walling et al. 2010 (Supporting Table 3). 
Supporting Table 1 Characteristics of the meerkat microsatellite kit. Panel=multiplex (Ssu1, Ssu2 \& Mm1) and co-loaded (OB) loci sets;

Tm=annealing temperatures; PCR product dilution factor=multiplex reactions are diluted in $\mathrm{H}_{2} \mathrm{O}$ whereas co-loaded reactions are diluted with each other. 


\begin{tabular}{|c|c|c|c|c|c|c|c|c|c|c|}
\hline Panel & $\begin{array}{l}\text { Locus } \\
\text { ( \& modifications } \\
\text { from original) }\end{array}$ & $\begin{array}{l}\text { GenBank } \\
\text { accession no. }\end{array}$ & $\begin{array}{l}\text { Origin \& } \\
\text { Reference }\end{array}$ & $\begin{array}{l}\text { 5'-3' primer sequences } \\
\text { (incl. 5' fluorescent label) }\end{array}$ & $\begin{array}{l}\mathrm{Tm} \\
\left({ }^{\circ} \mathrm{C}\right)\end{array}$ & $\begin{array}{l}\text { Repeat } \\
\text { motif } \\
\left(5^{\prime}-3^{\prime}\right) \\
\end{array}$ & $\% \mathrm{GC}$ & $\begin{array}{l}\text { Primer } \\
\text { conc. } \\
(\mu \mathrm{M})\end{array}$ & $\begin{array}{l}\mathrm{MgCl}_{2} \\
(\mathrm{mM})\end{array}$ & $\begin{array}{l}\text { PCR product } \\
\text { dilution factor }\end{array}$ \\
\hline \multirow[t]{4}{*}{ Ssu1 } & Ssu11.12 (-6bp) & $\underline{A F 271118}$ & Meerkat $^{1}$ & $\begin{array}{l}\text { F: (FAM) - CAGGAAATTTTCATCCTGGTAG } \\
\text { R: CTAGCTTTATTTTTCTCTGTGGC }\end{array}$ & 58 & (GT) & $\begin{array}{l}41 \\
39\end{array}$ & 0.07 & 1.50 & 1:11 \\
\hline & Ssu12.1 (+27bp) & AF271119 & Meerkat $^{1}$ & $\begin{array}{l}\text { F: (NED) - TTGTTTAAGCCACCCAGTCTG } \\
\text { R: CATTAAACCAGGACTGTTGCC }\end{array}$ & 58 & (AC) & $\begin{array}{l}48 \\
48\end{array}$ & 0.09 & 1.50 & \\
\hline & Ssu13.8 (+86bp) & $\underline{\text { AF271120 }}$ & Meerkat $^{1}$ & $\begin{array}{l}\text { F: (PET) -AGAACAGAAGTGCCTGAATGTG } \\
\text { R: GTCGTCATATCCTCCTCT }\end{array}$ & 58 & $(\mathrm{TC})(\mathrm{AC})$ & $\begin{array}{l}45 \\
50\end{array}$ & 0.41 & 1.50 & \\
\hline & Ssu13.9 (+135bp) & $\underline{\text { AF271121 }}$ & Meerkat $^{1}$ & $\begin{array}{l}\text { F: (FAM) - AACACACTTGAGGAATCTGACTC } \\
\text { R: TTGGATGCTTAACCGAGCTAC }\end{array}$ & 58 & (TG) & $\begin{array}{l}43 \\
48\end{array}$ & 0.17 & 1.50 & \\
\hline \multirow[t]{4}{*}{ Ssu2 } & Ssu14.14 (-33bp) & $\underline{\text { AF271122 }}$ & Meerkat $^{1}$ & $\begin{array}{l}\text { F: (NED) - ATTTGCTGAGAGTTTTCCCAAC } \\
\text { R: TTGCTTATACCAAGGAGCATTG }\end{array}$ & 60 & (AC) & $\begin{array}{l}41 \\
41\end{array}$ & 0.21 & 1.50 & $1: 7$ \\
\hline & Ssu10.4 (+7bp) & $\underline{\text { AF271117 }}$ & Meerkat $^{1}$ & $\begin{array}{l}\text { F: TTCTTTTCCCTGGAGGTAATG } \\
\text { R: (PET) - TAGCAGCAAATAGATTCATTGGG }\end{array}$ & 60 & (GT) & $\begin{array}{l}43 \\
39\end{array}$ & 0.26 & 1.50 & \\
\hline & Ssu7.1 (+19bp) & $\underline{\text { AF271115 }}$ & Meerkat $^{1}$ & $\begin{array}{l}\text { F: } \\
\text { R: (FAM) - ATCCCTTTAATGCATAGGCACAC }\end{array}$ & 60 & $(\mathrm{TC})(\mathrm{AC})$ & $\begin{array}{l}45 \\
36\end{array}$ & 0.23 & 1.50 & \\
\hline & Ssu8.5 & $\underline{\text { AF271116 }}$ & Meerkat $^{1}$ & $\begin{array}{l}\text { F: (VIC) - AAGTCAGGTGCTTAACTGACTGG } \\
\text { R: TGGAGTCACTCATTTGGTTTTG }\end{array}$ & 60 & $(\mathrm{CT})(\mathrm{CA})$ & $\begin{array}{l}48 \\
41\end{array}$ & 0.20 & 1.50 & \\
\hline \multirow[t]{5}{*}{ Mm1 } & $\operatorname{MmAAAC}(+5 b p)^{\star}$ & $\frac{\mathrm{AY} 142703}{\mathrm{AY} 142702}$ & Banded mongoose $^{2}$ & $\begin{array}{l}\text { F: TTTGCACTGACAACATGGAGC } \\
\text { R: (FAM) - TAAACCAGACTAGAAAGTGGAGC }\end{array}$ & 58 & (AAAC) & $\begin{array}{l}48 \\
43\end{array}$ & 0.11 & 1.50 & 1:10 \\
\hline & Mm18.1 (+1bp) & $\underline{A Y 155580}$ & Banded mongoose ${ }^{2}$ & $\begin{array}{l}\text { F: } \overline{(\text { VIC })} \text { - GTTTGATTATATTGTATACCTGAAGCAC } \\
\text { R: CTATTTTCTCAGTATAGCAGAAGGTG }\end{array}$ & 58 & $(A C)$ & $\begin{array}{l}32 \\
38\end{array}$ & 0.11 & 1.50 & \\
\hline & Mm7.5 (+14bp) & $\underline{\text { AY142694 }}$ & Banded mongoose $^{2}$ & $\begin{array}{l}\text { F: (NED) - AGGCAGGAAATGAGATGCAGA } \\
\text { R: AGTTGCTAGATACATGACTCAGG }\end{array}$ & 58 & (GT) & $\begin{array}{l}48 \\
43\end{array}$ & 0.16 & 1.50 & \\
\hline & Mm2.10 (+20bp) & $\underline{\text { AY142696 }}$ & Banded mongoose $^{2}$ & $\begin{array}{l}\text { F: (PET) -AAACTTACTGAGCTTCTCGTGTG } \\
\text { R: AAGTCCTCTCCTGCCAGATG }\end{array}$ & 58 & (GT) & $\begin{array}{l}43 \\
55\end{array}$ & 0.15 & 1.50 & \\
\hline & Mm18.2 (+50bp) & $\underline{A Y 142698}$ & Banded mongoose $^{2}$ & $\begin{array}{l}\text { F: (FAM) - TAGGATATGGAGGAATTGTTGCTG } \\
\text { R: CTTCTTAGAAATGTAGACTGTCATCC }\end{array}$ & 58 & (TG) & $\begin{array}{l}42 \\
38\end{array}$ & 0.40 & 1.50 & \\
\hline \multirow[t]{5}{*}{ OB } & FCA77 & $\underline{\text { AF130506 }}$ & $\mathrm{Cat}^{3}$ & $\begin{array}{l}\text { F: (NED) - GGCACCTATAACTACCAGTGTGA } \\
\text { R: ATCTCTGGGGAAATAAATTTTGG }\end{array}$ & 54 & (TG) & $\begin{array}{l}48 \\
35\end{array}$ & 0.40 & 2.50 & 1:16 \\
\hline & Ssu14.18 (-1bp) & AF271123 & Meerkat $^{1}$ & $\begin{array}{l}\text { F: (VIC) - TTGCACTACTCAAAAAGTGATGTC } \\
\text { R: ACAGTCCGCAAGCAAATTGG }\end{array}$ & 49 & (CA) & $\begin{array}{l}38 \\
50\end{array}$ & 0.40 & 2.50 & $1: 8$ \\
\hline & AHT130 & - & $\operatorname{Dog}^{4}$ & $\begin{array}{l}\text { F: (PET) - CCTCTCCTGGTAAGTGCTGC } \\
\text { R: TGGAACACTGGTCCCCAG }\end{array}$ & 51 & - & $\begin{array}{l}60 \\
61\end{array}$ & 0.40 & 2.50 & 1:3.2 \\
\hline & FCA045 & $\underline{\text { AF130489 }}$ & $\mathrm{Cat}^{3}$ & $\begin{array}{l}\text { F: TGAAGAAAAGAATCAGGCTGTG } \\
\text { R: (FAM) - GTATGAGCATCTCTGTGTTCGTG }\end{array}$ & 49 & (AC) & $\begin{array}{l}41 \\
48\end{array}$ & 0.40 & 2.50 & $1: 4$ \\
\hline & HG810 & $\underline{\mathrm{G} 02093}$ & Grey seal $^{5}$ & $\begin{array}{l}\text { F: AATTCTGAAGCAGCCCAAG } \\
\text { R: (VIC) - GAATTCTTTTCTAGCATAGGTTG }\end{array}$ & 49 & (AC) & $\begin{array}{l}47 \\
35\end{array}$ & 0.40 & 2.50 & $1: 4$ \\
\hline
\end{tabular}


*The two MmAAAC GenBank sequences appear to refer to the same cloned fragment.

${ }^{1}$ Griffin et al. (2001); ${ }^{2}$ Waldick et al. (2003); ${ }^{3}$ Menottii-Raymond \& O’Brien (1995); ${ }^{4}$ Holmes et al. (1995); ${ }^{5}$ Allen et al. (1995). 
Supporting Table 2 Meerkat microsatellite marker and population genetics summary statistics. Population genetic values were obtained from an analysis of the entire genotype dataset ( $n=1,494$ individuals) using CERvus 3.0.3 (Marshall et al. 1998). $H_{E}=$ expected heterozygosity; $H_{O}=$ observed heterozygosity; $H_{E}$ - $H_{O}=$ deviation from Hardy-Weinberg equilibrium including level of significance to which a locus deviates from equilibrium prior to Bonferroni correction; $N E_{-1 P}=$ non-exclusion probability of excluding a parent when lacking information on either of the parents; Null allele frequency=inferred frequency of null alleles. Genotyping error rates were calculated manually from repeat genotypes.

\begin{tabular}{|c|c|c|c|c|c|c|c|c|c|}
\hline Locus & $\begin{array}{l}\text { No. of } \\
\text { individuals }\end{array}$ & $\begin{array}{l}\text { Allele size } \\
\text { range (bp) }\end{array}$ & $\begin{array}{l}\text { No. of } \\
\text { alleles }\end{array}$ & $H_{E}$ & $H_{0}$ & $H_{E}-H_{O}$ & $N E_{-1 P}$ & $\begin{array}{l}\text { Null allele } \\
\text { frequency }\end{array}$ & $\begin{array}{l}\text { Genotyping } \\
\text { error rate }\end{array}$ \\
\hline Ssu11.12 & 1,465 & $109-127$ & 9 & 0.799 & 0.791 & $0.008^{*+* x}$ & 0.583 & -0.0094 & 0.0376 \\
\hline Ssu12.1 & 1,442 & $161-183$ & 11 & 0.820 & 0.829 & $-0.009^{*+1 * x}$ & 0.526 & -0.0062 & 0.0309 \\
\hline Ssu13.8 & 1,449 & 213-239 & 11 & 0.720 & 0.620 & $0.100^{\text {stot }}$ & 0.679 & +0.0717 & 0.0803 \\
\hline Ssu13.9 & 1,444 & $255-281$ & 8 & 0.664 & 0.668 & -0.004 & 0.771 & -0.0044 & 0.0806 \\
\hline Ssu14.14 & 1,468 & $72-88$ & 9 & 0.798 & 0.817 & $-0.019^{\text {t*t* }}$ & 0.572 & -0.0139 & 0.0507 \\
\hline Ssu10.4 & 1,454 & $120-147$ & 11 & 0.774 & 0.783 & $-0.009^{*}$ & 0.609 & -0.0060 & 0.0341 \\
\hline Ssu7.1 & 1,464 & $156-177$ & 9 & 0.811 & 0.817 & $-0.006^{*+* x}$ & 0.549 & -0.0033 & 0.0279 \\
\hline Ssu8.5 & 1,434 & $205-240$ & 15 & 0.890 & 0.902 & $-0.012^{* * *}$ & 0.363 & -0.0071 & 0.0186 \\
\hline MmAAAC & 1,464 & $113-121$ & 3 & 0.581 & 0.574 & 0.007 & 0.831 & +0.0060 & 0.0279 \\
\hline Mm18.1 & 1,460 & $140-164$ & 4 & 0.263 & 0.267 & -0.004 & 0.965 & -0.0100 & 0.0215 \\
\hline Mm7.5 & 1,445 & $180-223$ & 12 & 0.638 & 0.619 & $0.019^{i+x+x}$ & 0.758 & +0.0139 & 0.0602 \\
\hline Mm2.10 & 1,455 & $170-194$ & 6 & 0.678 & 0.693 & -0.015 & 0.734 & -0.0130 & 0.0219 \\
\hline Mm18.2 & 1,438 & $251-275$ & 8 & 0.731 & 0.751 & $-0.020^{\text {t*t }}$ & 0.685 & -0.0161 & 0.0133 \\
\hline FCA77 & 1,479 & $110-127$ & 4 & 0.432 & 0.414 & 0.018 & 0.907 & +0.0203 & 0.0182 \\
\hline Ssu14.18 & 1,395 & $122-148$ & 11 & 0.710 & 0.680 & $0.030^{* * *+}$ & 0.694 & +0.0170 & 0.0312 \\
\hline AHT130 & 1,375 & $136-158$ & 11 & 0.750 & 0.769 & $-0.019^{*+1 * t}$ & 0.631 & -0.0163 & 0.0173 \\
\hline FCA045 & 1,390 & $159-181$ & 10 & 0.792 & 0.796 & $-0.004^{*+* x}$ & 0.576 & -0.0032 & 0.0254 \\
\hline HG810 & 1,429 & $193-233$ & 13 & 0.763 & 0.754 & $0.009^{4+*+1}$ & 0.61 & +0.0009 & 0.0205 \\
\hline Mean & 1,442 & - & 9 & 0.700 & 0.697 & 0.003 & - & - & - \\
\hline
\end{tabular}

${ }^{*} p<0.05 ;{ }^{* *} p<0.01 ;{ }^{* * *} p<0.001$. 
Supporting Table 3 Comparison of the parentage inference performance of COLONY2 and MASTERBAYES. The programs were compared following Walling et al. 2010: matching assignments between the programs are split into those where both programs assigned the same parent (Match assigned) or where both programs assigned no parent (Match unassigned). Mismatches are split into cases where COLONY2 assigned a parent but MASTERBAYES did not (COLONY2 assigned) and vice versa (MASTERBAYES assigned), and cases where both assigned a parent but they did not match (Assignments mismatch). Comparisons include COLONY2 ‘dummy’ parentages, which had been attributed to an identified candidate mother/father.

\begin{tabular}{llllll}
\hline Parent & $\begin{array}{l}\text { Match } \\
\text { assigned }\end{array}$ & $\begin{array}{l}\text { Match } \\
\text { unassigned }\end{array}$ & $\begin{array}{l}\text { COLONY2 } \\
\text { assigned }\end{array}$ & $\begin{array}{l}\text { MASTERBAYES } \\
\text { assigned }\end{array}$ & $\begin{array}{l}\text { Assignment } \\
\text { mis-matched }\end{array}$ \\
\hline Maternities & 993 & 118 & 301 & 111 & 60 \\
Paternities & 788 & 285 & 420 & 21 & 69 \\
\hline
\end{tabular}


Supporting Table 4 Pair-wise correlation coefficients among explanatory variables. Numbers above the diagonal give the correlation value $(r)$ at the litter level. All variables are consistent within litters expect for in case of mixed paternity litters $(n=5)$ where pup $F$ was averaged. Only emergence mass (EM) ages are included. NS refers to no significant correlation.

\begin{tabular}{|c|c|c|c|c|c|c|c|c|c|c|}
\hline & Pup F & Pup age & Pup age ${ }^{2}$ & Litter size & Mother age & Mother mass & Helper no. & Lactator no. & Season & Rainfall \\
\hline Pup $F$ & - & NS & NS & $-0.245^{* *}$ & NS & NS & $0.167^{*}$ & NS & NS & NS \\
\hline Pup EM age & & - & $0.993^{* * *}$ & NS & NS & NS & $0.218^{*}$ & NS & NS & NS \\
\hline Pup EM age 2 & & & - & NS & NS & NS & $0.226^{*}$ & NS & NS & NS \\
\hline Litter size & & & & - & NS & $0.234^{* *}$ & $-0.204^{* *}$ & NS & $-0.192^{*}$ & NS \\
\hline Mother age & & & & & - & $0.427^{* * *}$ & $0.257^{* * *}$ & $-0.155^{*}$ & NS & NS \\
\hline Mother mass & & & & & & - & NS & $-0.168^{*}$ & NS & $-0.163^{*}$ \\
\hline Helper no. & & & & & & & - & $0.317^{* * *}$ & NS & NS \\
\hline Lactator no. & & & & & & & & - & $-0.243^{* *}$ & $0.307^{* * *}$ \\
\hline Season & & & & & & & & & - & $-0.228^{* *}$ \\
\hline
\end{tabular}


Supporting Table 5 Summary of final minimal models of skull and forearm length. Final minimal models were achieved by sequentially dropping the least significant terms based on Wald statistics until only significant $(p>0.05)$ terms remained. NS terms are not significant and therefore removed. Variables in italics are non-significant but retained in the final minimal models based on Wald statistics. Total deviance explained by all fixed effects=9.865\% (skull length) and 5.532\% (forearm length).

\begin{tabular}{|c|c|c|c|c|c|c|}
\hline \multirow[b]{2}{*}{ Fixed effects ${ }^{*}$} & \multicolumn{3}{|c|}{ Skull length $(\mathrm{mm})$} & \multicolumn{3}{|c|}{ Forearm length $(\mathrm{mm})$} \\
\hline & Estimate $\pm \mathrm{SE}$ & $F_{d f}$ & $p$-value & Estimate $\pm \mathrm{SE}$ & $\mathrm{F}_{\mathrm{df}}$ & $p$-value \\
\hline Pup $F$ & NS & - & - & NS & - & - \\
\hline Sex & NS & - & - & $-0.384 \pm 0.228$ & $3.334_{1,241}$ & 0.113 \\
\hline Pup age & $0.023 \pm 0.005$ & $29.603_{1,327}$ & $<0.001^{\ddagger}$ & $0.025 \pm 0.007$ & $13.082_{1,241}$ & $0.003^{\ddagger}$ \\
\hline Pup age $^{2}$ & NS & - & - & NS & - & - \\
\hline Litter size & $-0.483 \pm 0.166$ & $5.461_{1,327}$ & $0.009^{\ddagger}$ & NS & - & - \\
\hline Mother age & $-0.001 \pm<0.001$ & $9.398,327$ & $<0.001^{\ddagger}$ & NS & - & - \\
\hline Mother mass & $0.010 \pm 0.003$ & $8.406_{1,327}$ & $0.003^{\ddagger}$ & NS & - & - \\
\hline Lactator number & $0.280 \pm 0.136$ & $1.413_{1,327}$ & 0.054 & $0.286 \pm 0.152$ & $1.322_{1,241}$ & 0.079 \\
\hline $\mathrm{YOB}^{\dagger}$ & - & $4.574_{5,327}$ & - & - & $3.937_{3,241}$ & - \\
\hline 2000 & $0.902 \pm 0.768$ & - & 0.255 & - & - & - \\
\hline 2004 & $1.555 \pm 0.746$ & - & 0.052 & - & - & - \\
\hline 2005 & $-0.313 \pm 0.658$ & - & 0.640 & $-2.671 \pm 1.161$ & - & 0.036 \\
\hline 2006 & $0.709 \pm 0.695$ & - & 0.321 & $-2.809 \pm 1.186$ & - & 0.032 \\
\hline 2007 & $-1.476 \pm 1.134$ & - & 0.209 & $-5.079 \pm 1.556$ & - & $0.005^{\ddagger}$ \\
\hline Season & $-1.111 \pm 0.388$ & $0.920_{1,327}$ & $0.010^{\ddagger}$ & NS & - & - \\
\hline Rainfall & NS & - & - & NS & - & - \\
\hline Random effects & & Variance & $\%$ & & Variance & $\%$ \\
\hline Mother ID & & 0.034 & 2.022 & & $6.143 * 10^{-15}$ & $<0.001$ \\
\hline Litter ID & & 2.310 & 49.35 & & 2.889 & 50.799 \\
\hline Birth group ID & & 0.090 & 5.354 & & 0.000 & $<0.001$ \\
\hline Residual & & 2.247 & 48.003 & & 2.481 & 46.201 \\
\hline
\end{tabular}


${ }^{*}$ NS variables not fitted in the final minimal model: mother $F$; mother status; mother age ${ }^{2}$; helper number and helper number ${ }^{2}$.

${ }^{\dagger}$ Reference level for pup year of birth is 1999 (skull length) and 2004 (forearm length).

${ }^{\ddagger}$ Significant after sequential Bonferroni correction. 


\section{References}

Griffin AS, Nürnberger B, Pemberton JM (2001) A panel of microsatellites developed for meerkats (Suricata suricatta) by cross-species amplification and species-specific cloning. Molecular Ecology Notes 1, 83-85.

Griffin AS, Pemberton JM, Brotherton PNM, et al. (2003) A genetic analysis of breeding success in the cooperative meerkat (Suricata suricatta). Behavioural Ecology 14, 472480.

Hadfield JD, Richardson DS, Burke T (2006) Towards unbiased parentage assignment: combining genetic, behavioural and spatial data in a Bayesian framework. Molecular Ecology 15, 3715-3730.

Marshall TC, Slate J, Kruuk LEB, Pemberton JM (1998) Statistical confidence for likelihoodbased paternity inference in natural populations. Molecular Ecology 7, 639-655.

Spong GF, Hodge SJ, Young AJ, Clutton-Brock TH (2008) Factors affecting the reproductive success of dominant male meerkats. Molecular Ecology 17, 2287-2299.

Walling CA, Pemberton JM, Hadfield JD, Kruuk LEB (2010) Comparing parentage inference software: reanalysis of a red deer pedigree. Molecular Ecology 19.

Wang J (2004) Sibship Reconstruction From Genetic Data With Typing Errors. Genetics 166, 1963-1979.

Wang J, Santure AW (2009) Parentage and Sibship Inference From Multi-locus Genotype Data Under Polygamy. Genetics 181, 1579-1594. 